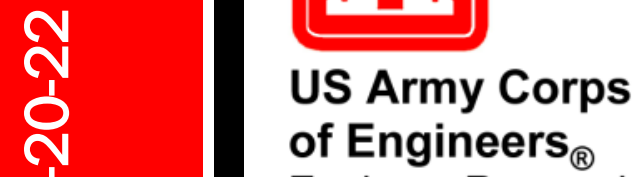

\title{
WERDC
}

Engineer Research and

Development Center

\subsection{ERDC Basic Research}

\section{Microbiological Indicators Reflect Patterns of Life}

Alison K. Thurston, Andrew Hoisington, Andmorgan Fisher,

Shelby A. Rosten, Elizabeth J. Corriveau, Robert M. Jones, and Robyn A. Barbato

Detect specific biosignature on office items
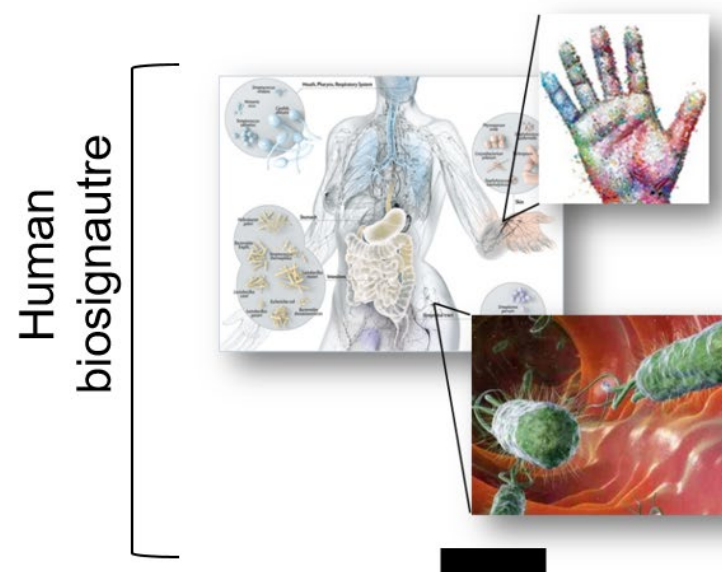
The U.S. Army Engineer Research and Development Center (ERDC) solves the nation's toughest engineering and environmental challenges. ERDC develops innovative solutions in civil and military engineering, geospatial sciences, water resources, and environmental sciences for the Army, the Department of Defense, civilian agencies, and our nation's public good. Find out more at www.erdc.usace.army.mil.

To search for other technical reports published by ERDC, visit the ERDC online library at https://erdclibrary.on.worldcat.org/discovery. 


\title{
Microbiological Indicators Reflect Patterns of Life
}

\author{
and Robyn A. Barbato \\ U.S. Army Engineer Research and Development Center (ERDC) \\ Cold Regions Research and Engineering Laboratory (CRREL) \\ 72 Lyme Road \\ Hanover, NH 03755-1290 \\ Andrew Hoisington \\ Department of Systems Engineering and Management \\ Air Force Institute of Technology \\ Wright-Patterson AFB, $\mathrm{OH} 45433$ \\ Andmorgan Fisher \\ U.S. Army Engineer Research and Development Center (ERDC) \\ Geospatial Research Laboratory (GRL) \\ Cude Bldg. 2592 \\ 7701 Telegraph Road \\ Alexandria, VA 22315-3864
}

Alison K. Thurston, Shelby A. Rosten, Elizabeth J. Corriveau, Robert M. Jones,

Final Report

Approved for public release; distribution is unlimited.

Prepared for Headquarters, U.S. Army Corps of Engineers

Washington, DC 20314-1000

Under ERDC 6.1 Basic Research, PE 611102 / Project T24 / Task A1000 


\section{Abstract}

Resolving patterns of human movement, specifically for actors of interest, in an urban environment is an extremely challenging problem because of the dynamic nature of human movement. This research effort explores a highly unconventional approach, addressing residual or lingering signatures of interest to the Army in an urban operation. Research suggests that unconventional signatures commonly associated with human presence or prior occupation of a space, such as microbes attached to skin cells or in the gut, may linger for an extended amount of time. In this scoping study, our objectives were to detect microbial communities in the built environment, to examine microbial community composition, and to investigate the longevity of a microbial signature. To do so, we conducted a controlled study to obtain a mechanistic understanding of the fidelity of the biological signatures in the built environment, with a particular focus on their longevity and stability.

DISCLAIMER: The contents of this report are not to be used for advertising, publication, or promotional purposes. Citation of trade names does not constitute an official endorsement or approval of the use of such commercial products. All product names and trademarks cited are the property of their respective owners. The findings of this report are not to be construed as an official Department of the Army position unless so designated by other authorized documents. 


\section{Contents}

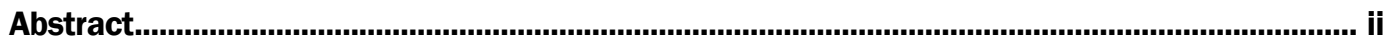

Figures and Tables....................................................................................................................................iv

Preface .................................................................................................................................. vi

Acronyms and Abbreviations ..................................................................................................... vii

1 Introduction ......................................................................................................................... 1

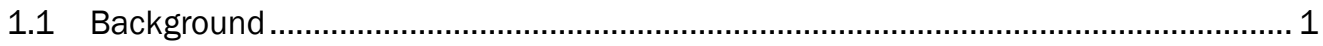

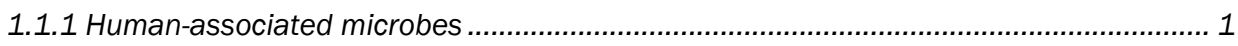

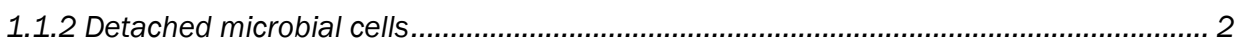

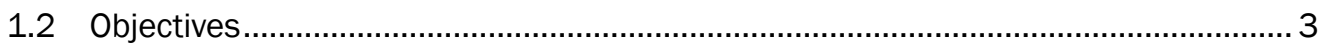

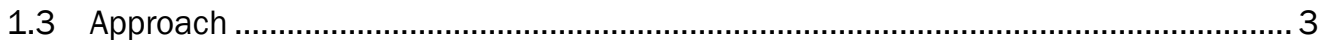

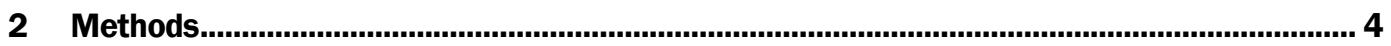

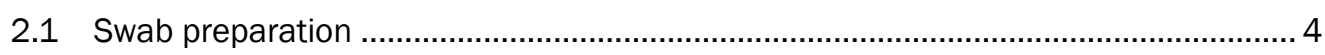

2.2 Sample collection .......................................................................................... 4

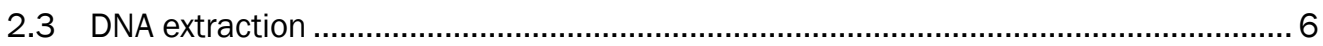

2.4 Quantitative polymerase chain reaction ......................................................... 6

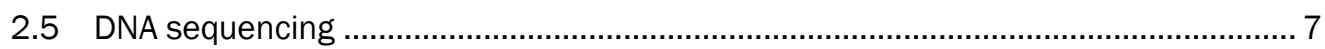

2.6 Sequence quality control and processing ............................................................. 8

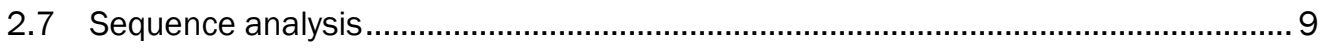

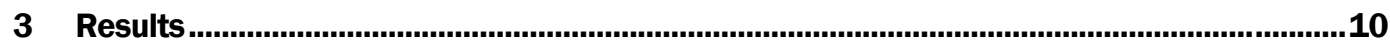

3.1 Detection of biological signatures in the built environment................................... 10

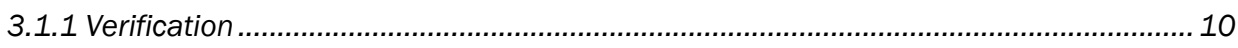

3.1.2 Removal of biological signatures through cleaning .................................................. 12

3.1.3 Investigation of wetting agents................................................................................ 14

3.2 Analysis of biological signatures on objects in the built environment.....................15

3.2.1 Survey of biological signatures on surfaces................................................................... 15

3.2.2 Microbial signatures used for fingerprinting............................................................... 19

3.3 Community succession in the built environment................................................... 21

3.3.1 Longitudinal changes in microbiomes of the built environment .................................. 21

3.3.2 Microbiome response to perturbation......................................................................... 23

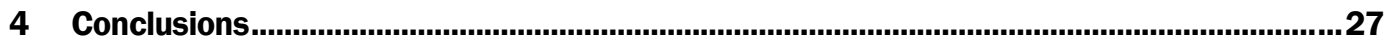

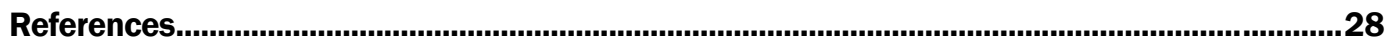

Appendix A: Supplemental Figure ..................................................................................... 34

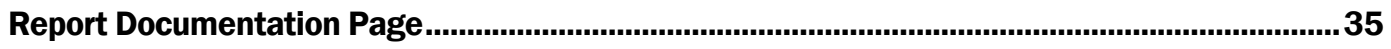




\section{Figures and Tables}

\section{Figures}

1 Sterile swabs presoaking in sterile swabbing solution prior to sample collection

2 Items sampled for biological signatures. Red polygons depict the areas that were swabbed. Each item was swabbed three times (R1, R2 or R3). Swabbed surfaces included $(A)$ pen, $(B)$ mouse, $(C)$ microwave, $(D)$ handicap Button, (E) floor (section 3.3.2), ( $F$ ) floor (section 3.3.1), and $(G)$ doorknob.

3 Bacterial abundance detected in the built environment. The total bacterial biomass was determined by qPCR from selected samples: floor, computer mouse, pen, swabbing controls, and extraction blanks. The reported $16 \mathrm{~S}$ rRNA gene copy number are the average of 3 or 4 replicates. Error bars represent the standard error. An asterisk denotes a reported average that includes values extrapolated outside the lower end of the standard curve

$4 \quad \mathrm{PCOA}$ plot displaying microbial community dissimilarity between the controls (swab and blank) and built-environment samples using the BrayCurtis dissimilarity metric

5 Box plots showing Shannon diversity of all samples

6 Removal of biological signatures in the built environment. Plots of $(A)$ total bacterial biomass and $(B)$ PCoA dissimilarity using the Bray-Curtis dissimilarity metric display signatures detected from a computer mouse and a door handle where one half of the object was cleaned prior to sampling. Error bars represent the standard error. An asterisk denotes a reported average that includes values extrapolated outside the lower end of the standard curve

$7 \quad$ PCoA diversity plot displaying similarities between samples collected from the floor and carpet by using either phosphate-buffered saline (PBS) or Tween20 in a $\mathrm{NaCl}$ solution (T20) as a wetting agent. Ordination was generated using the Bray-Curtis dissimilarity metric

$8 \quad$ PCoA plot displaying dissimilarity between communities collected on indicated surface types in the built environment. Ordination was generated using the Bray-Curtis dissimilarity metric

9 Bar chart displaying relative abundance of bacteria detected on objects in the built environment reported at the genus level. The legend lists the top twenty taxa

10 PCoA plot displaying similarities between communities collected from computer mice and pens at two individuals' workstations. Ordination was generated using the Bray-Curtis dissimilarity metric

11 Average relative abundance of Staphylococcus, Acinetobacter, and

Pseudomonas on items collected at workstation 1 and workstation 2.

Sampling was performed in triplicate. Averages and standard deviations were calculated from the relative abundance

12 PCoA plot displaying biological signatures detected on the floor after cleaning ( $\left.t_{0}\right), 1$ day $\left(t_{1}\right)$, and 43 days $\left(t_{43}\right)$. Arrows indicate the progression of the community. Ordination was generated using the Bray-Curtis dissimilarity metric 
13 Bar chart displaying relative abundance at the genus level of floor samples immediately ( $\left.t_{0}\right), 1$ day ( $\left.t_{1}\right)$, and 43 days ( $\left.t_{43}\right)$ after cleaning. Swabbing at each time point was performed in triplicate. The legend lists the top twenty taxa

14 Diagram of experimental setup (not to scale). Each location was sampled at the beginning of the experiment ( $\left.t_{0}\right)$ and 43 days $\left(t_{43}\right)$ later.

15 PCoA plot displaying biological signatures detected on clean and unclean squares located within three sections of the floor (S1, S2, and S3) at the start of the experiment ( $\left.t_{0}\right)$ and 43 days ( $\left.t_{43}\right)$ later. Arrows indicate the progression of the community. Ordination was generated based on the Bray-Curtis dissimilarity metric.

16 Relative abundance of floor samples immediately $\left(t_{0}\right)$ and 43 days ( $\left.t_{43}\right)$ after the disturbance event (cleaning). Swabbing was performed in triplicate at each square for each time point. The legend lists the top twenty taxa

Tables

1 Sample-collection information 5 


\section{Preface}

This study was conducted for the U.S. Army Corps of Engineers, under Engineer Research and Development Center (ERDC) 6.1 Basic Research PE 611102 / Project T24 / Task A10oo.

The work was performed by the Biogeochemical Sciences Branch of the Research and Engineering Division, ERDC Cold Regions Research and Engineering Laboratory (CRREL). At the time of publication, Dr. Steven Peckham was Acting Branch Chief; Mr. J. D. Horne was Division Chief; and Dr. Robert Davis was Chief Scientist for Geospatial Research and Engineering and Technical Director for Army programs at CRREL. The Deputy Director of ERDC-CRREL was Mr. David B. Ringelberg, and the Director was Dr. Joseph L. Corriveau.

The work was also performed by the Data and Signature Analysis Branch of the Topography, Imagery, and Geospatial Research Division, ERDC Geospatial Research Laboratory (GRL). At the time of publication, Ms. Jennifer L. Smith was Branch Chief; Ms. Martha Kiene was Division Chief; and Mr. Ritchie Rodebaugh was Technical Director for Geospatial Research and Engineering. The Deputy Director of ERDCGRL was Ms. Valerie L. Carney, and the Director was Mr. Gary Blohm.

COL Teresa A. Schlosser was Commander of ERDC, and Dr. David W. Pittman was the Director. 


\section{Acronyms and Abbreviations}

$\begin{array}{ll}\text { ASV } & \text { Amplicon Sequence Variants } \\ \text { bp } & \text { Base Pair } \\ \text { CRREL } & \text { Cold Regions Research and Engineering Laboratory } \\ \text { ERDC } & \text { Engineer Research Development Center } \\ \text { GRL } & \text { Geospatial Research Laboratory } \\ \text { NaCl } & \text { Sodium Chloride } \\ \text { PBS } & \text { Phosphate-Buffered Saline } \\ \text { PCoA } & \text { Principal Coordinates Analysis } \\ \text { PCR } & \text { Polymerase Chain Reaction } \\ \text { RDP } & \text { Ribosomal Database Project } \\ \text { qPCR } & \text { Quantitative Polymerase Chain Reaction } \\ \text { T20 } & \text { Tween2o in a NaCl Solution }\end{array}$





\section{Introduction}

\subsection{Background}

\subsubsection{Human-associated microbes}

Humans are a habitat for microorganisms, with various bacterial and fungal species preferentially inhabiting specific areas of the body, from the skin to the gut (Sharma et al. 2019; Grice and Segre 2011). In fact, human cells are considerably outnumbered by microbial cells (Qin et al. 2010). Recent key research recognized the importance of human-associated microbiota in human function, even at the psychological level. Large programs such as the Human Microbiome Project addressed the microbiome by investigating microbiota living in and on healthy or diseased humans, using advanced techniques, such as high throughput DNA technology $\mathrm{CHu}-$ man Microbiome Project Consortium 2012). The Human Microbiome Project and others have identified common microbiota typical to particular parts of the human body, such as Propionibacterium on skin and Bacteroides in the human gut (Qin et al. 2010; Chen and Tsao 2013; SanMiguel and Grice 2015).

Compelling research findings show that the genetic information within these microbiomes can be accurately used to sociologically and medically group populations by country of origin (Holbert et al. 2015; Leung et al. 2015; Pehrsson et al. 2016), distinct culture groups (Nishijima et al. 2016), or exposure to antibiotics (Hu et al. 2013). Interestingly, one specific gut bacterium, Helicobacter pylori, is present in half the human population. Each of the seven distinct global strains are associated with a particular geographic origin (Nishijima et al. 2016), making it a potential identifier of an individual's prior location. Even more compelling, Tung et al. (2015) found associations between gut microbiota and social groupings after controlling for diet, kinship, and shared environments in baboons. Furthermore, the skin microbial communities of individuals from one region can be accurately distinguished from other racial groups (Hospodsky et al. 2014; Leung et al. 2015; Gupta et al. 2017). Therefore, current research of the attached microbiome reveals differences across groups of individuals and may be used as a tool to provide fundamental knowledge of exposure patterns of microbes associated with human cells. However, it is not 
known whether the association between the microbial signature and geographic location remains strong when the microbial signature lingers in the human-made environment (built environment).

\subsubsection{Detached microbial cells}

Microbes in indoor dust have been studied extensively with the aims of improving indoor air quality and human health (Rintala et al. 2008), understanding microbial survival on different building substrates (Kelley and Gilbert 2013), and linking human presence with associated microbiota in the environment (Lax et al. 2014). Unlike detached fungi, detached bacteria are more promising candidates to detect human movement in the built environment; they do not change significantly across seasons (Rintala et al. 2008; Adams et al. 2013; Barberán et al. 2015) and are more closely related to the number and types of occupants in a home (Barberán et al. 2015; Dannemiller et al. 2017).

Because this is such a nascent field, recent literature is both disjointed and sometimes conflicting. For instance, Luongo et al. (2017) found that microbiota collected from airborne dust in a dormitory differed between genders; however, the longevity of the signatures was not investigated. In another study examining the surfaces of public restrooms, ecological succession of human-associated microbiota showed large changes in community succession in the first five hours after the closing of the bathrooms but minimal changes over the next two months (Gibbons et al. 2015). In contrast, a longitudinal study of families in actively used homes found that a person's absence from the home for a few days corresponded to a decrease in that person's hand-, foot-, and nose-associated contributions to the home's microbiome (Lax et al. 2014), suggesting that the indoor microbiome is indeed dynamic. Sharma et al. (2019) took it a step further through a longitudinal study of cohabitation among United States Air Force Academy cadets and determined that the skin microbiota is sensitive to occupancy while the gut microbiome was not.

Questions remain regarding the short-term changes in microbial community succession. In fact, both Weikl et al. (2016) and Pakpour et al. (2016) claim that spatial and temporal changes in indoor bacterial and archaeal communities in the built environment are still poorly understood. Their assessment is corroborated by an explosion of recent studies that range 
from the skin-associated microbiome to large-scale studies in the built environment, including metropolitan areas. Though it is published that microbiota found in dust can indicate gender (Luongo et al. 2017), colonize a home within three days, and decline once the person leaves the home (Lax et al. 2014), more research is needed to discern the stability of the signature, particularly under varying environmental conditions and when occupancy changes.

\subsection{Objectives}

The goal of this research was to survey biological signatures on office items present in the built environment. To do so, we outlined the following objectives:

1. Test for the detection of biological signatures in the built environment.

2. Analyze biological signatures found on objects in the built environment.

3. Investigate community succession in the built environment

\subsection{Approach}

We conducted a series of studies examining the microbial communities in the built environment. Samples were collected from items and surfaces around a working laboratory, including both office spaces and laboratory spaces. To assess if biological signatures could be detected in the built environment, we quantified the total bacterial biomass using quantitative polymerase chain reaction (qPCR). To analyze both the bacterial communities in the built environment and the longevity of the microbial signatures, we performed and analyzed 16S rRNA gene sequencing. Additionally, we used graphical and statistical methods to compare the microbial communities on the tested surfaces. 


\section{Methods}

\subsection{Swab preparation}

Swab preparation and post-sample-collection swab processing were performed in a biohood. Three or four sterile cotton-tipped swabs (Puritan, SKU\# 806-WC) were added to a Whirl-Pak bag (1 bag per surface sample) containing $1 \mathrm{~mL}^{*}$ of sterile swabbing solution (Figure 1). The swabbing solution was either $1 \mathrm{x}$ phosphate-buffered saline (PBS) at a $\mathrm{pH}$ of 7.4 or $0.1 \%$ Tween20 in $0.15 \mathrm{M} \mathrm{NaCl}^{+}$(T20). Swabs were completely saturated with the solution prior to sampling the surfaces. After swabbing the indicated surface (described in section 2.2), swabs were placed back into the sterile Whirl-Pak bag. The wood portion of the sterile cotton swab was removed using flame-treated wire cutters and tweezers. The cut swab was prepared for DNA extraction by placing it in a Qiagen PowerSoil DNA extraction PowerBead tube. The tubes with the cotton swabs were stored at $-20^{\circ} \mathrm{C}$ until DNA extraction was performed (described in section 2.3).

Figure 1. Sterile swabs presoaking in sterile swabbing solution prior to sample collection.

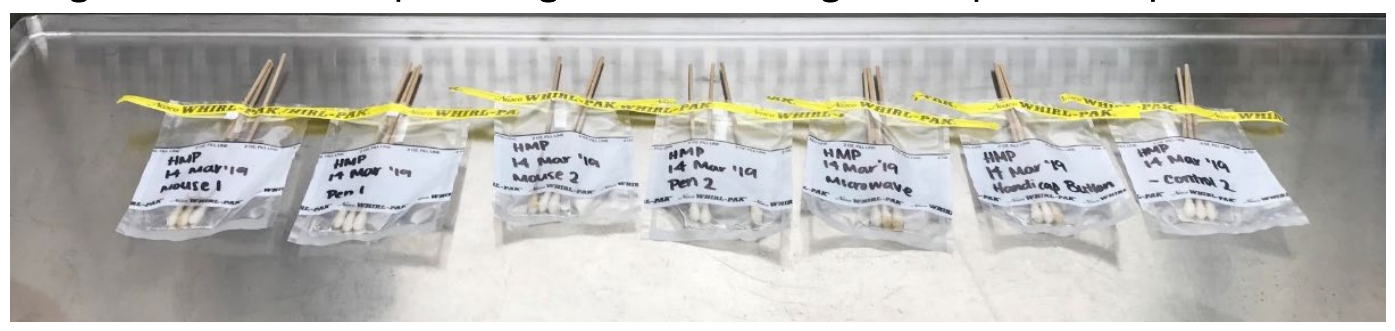

\subsection{Sample collection}

Swabbing was performed in triplicate (replicates 1, 2, and 3) unless indicated otherwise. The sterile presoaked cotton swab was moved back and forth on the sampling area for ten seconds while rotating the swab. Table 1 and Figure 2 provide details for swabbed items.

\footnotetext{
* For a full list of the spelled-out forms of the units of measure used in this document, please refer to U.S. Government Publishing Office Style Manual, 31st ed. (Washington, DC: U.S Government Publishing Office, 2016), 248-252, https://www.govinfo.gov/content/pkg/GPO-STYLEMANUAL-2016/pdf/GPO-STYLEMANUAL-2016.pdf.

† Sodium chloride.
} 
Table 1. Sample-collection information.

\begin{tabular}{|c|c|c|c|c|}
\hline Item & Description & $\begin{array}{l}\text { Reference } \\
\text { Figure }\end{array}$ & Objective & $\begin{array}{l}\text { Swabbing } \\
\text { Solution }\end{array}$ \\
\hline Carpet & $\begin{array}{l}\text { Three areas of an office carpet were swabbed (not } \\
\text { adjacent to each other) with solution. Swab areas were } \\
\text { approximately } 10 \mathrm{~cm} \text { in length. }\end{array}$ & $N / A$ & 1 and 2 & PBS or T20 \\
\hline $\begin{array}{l}\text { Computer } \\
\text { Mouse }\end{array}$ & $\begin{array}{l}\text { Swabbing occurred on the left and right sides (R1 and } \\
\mathrm{R} 2 \text {, respectively) and below the scrolling wheel (R3). }\end{array}$ & Figure 2B & 1 and 2 & T20 \\
\hline $\begin{array}{l}\text { Computer } \\
\text { Mouse } \\
\text { (section 3.1.2) }\end{array}$ & $\begin{array}{l}\text { The right side of the mouse was swabbed in triplicate. } \\
\text { The left side was cleaned with } 70 \% \text { ethanol, followed by } \\
\text { DNA Away and RNase Away. After cleaning, the left side } \\
\text { was swabbed in triplicate. }\end{array}$ & N/A & 1 & T20 \\
\hline Doorknob & $\begin{array}{l}\text { The top (shown as R1 and R2) and back (not shown) of } \\
\text { the doorknob were swabbed. The left side was cleaned } \\
\text { with } 70 \% \text { ethanol, followed by DNA Away and RNase } \\
\text { Away. After cleaning, the bottom (not shown) and front } \\
\text { (shown as R3) were swabbed. }\end{array}$ & Figure $2 \mathrm{G}$ & 1 & T20 \\
\hline $\begin{array}{l}\text { Floor } \\
\text { (section 3.1.3) }\end{array}$ & $\begin{array}{l}\text { Three areas of a laboratory floor were swabbed (not } \\
\text { adjacent to each other) with solution. Swab areas were } \\
\text { approximately } 10 \mathrm{~cm} \text { in length. }\end{array}$ & N/A & 1 and 2 & PBS or T20 \\
\hline $\begin{array}{l}\text { Floor } \\
\text { (section 3.3.1) }\end{array}$ & $\begin{array}{l}\text { A } 10 \times 10 \mathrm{~cm} \text { square was demarked with tape. The } \\
\text { square was cleaned with } 70 \% \text { ethanol, followed by DNA } \\
\text { Away and RNase Away. Immediately after cleaning, } \\
\text { three areas of the square were swabbed }\left(t_{0}\right) \text {. The } \\
\text { square was swabbed again after } 24 \text { hours }\left(t_{1}\right) \text { and } 43 \\
\text { days }\left(t_{43}\right) .\end{array}$ & Figure $2 \mathrm{~F}$ & 1 and 3 & $\begin{array}{l}\text { PBS }\left(t_{43}\right) \text { or } \\
\text { T20 }\left(t_{0}\right. \\
\left.\text { and } t_{1}\right)\end{array}$ \\
\hline $\begin{array}{l}\text { Floor } \\
\text { (section 3.3.2) }\end{array}$ & $\begin{array}{l}\text { Three sections of a laboratory floor, each containing } \\
\text { two squares, were demarked using tape (squares } \\
\text { within a pair were } ~ 14.5 \mathrm{~cm} \text { apart). At each section, } \\
\text { one square was swabbed without being cleaned. After } \\
\text { all three "unclean" squares were sampled, then the } \\
\text { "clean" squares were cleaned with } 70 \% \text { ethanol, } \\
\text { followed by DNA Away and RNase Away. After the } \\
\text { cleaning protocol, the "clean" squares were swabbed in } \\
\text { triplicate. All squares were swabbed again after } 43 \\
\text { days }\left(t_{43}\right) .\end{array}$ & $\begin{array}{l}\text { Figure 2E } \\
\text { and } \\
\text { Figure } 14\end{array}$ & 1 and 3 & $\begin{array}{l}\text { PBS }\left(t_{43}\right) \text { or } \\
\text { T20 (to) }\end{array}$ \\
\hline $\begin{array}{l}\text { Handicap } \\
\text { Button for } \\
\text { Automatic } \\
\text { Doors }\end{array}$ & $\begin{array}{l}\text { Swabbing occurred in straight lines from top to bottom } \\
\text { in three parallel regions of the automatic door opener. }\end{array}$ & Figure 2D & 1 and 2 & T20 \\
\hline Microwave & $\begin{array}{l}\text { Swabbing occurred in straight lines from top to bottom } \\
\text { in three parallel regions of the number pad on the } \\
\text { microwave. }\end{array}$ & Figure 2C & 1 and 2 & T20 \\
\hline $\begin{array}{l}\text { Negative } \\
\text { Controls }\end{array}$ & $\begin{array}{l}\text { Swabs were presoaked with the appropriate buffer. } \\
\text { Swabbing controls were carried out in quadruplicate. }\end{array}$ & N/A & 1,2 , and 3 & PBS or T20 \\
\hline Pen & $\begin{array}{l}\text { Swabbing occurred along the length of the pen on } \\
\text { either side of the clip and on the side opposite the clip. }\end{array}$ & Figure 2A & 1 and 2 & T20 \\
\hline
\end{tabular}


Figure 2. Items sampled for biological signatures. Red polygons depict the areas that were swabbed. Each item was swabbed three times (R1, R2 or R3). Swabbed surfaces included $(A)$ pen, $(B)$ mouse, $(C)$ microwave, $(D)$ handicap Button, $(E)$ floor (section 3.3.2), $(F)$ floor (section 3.3.1), and $(G)$ doorknob.

A

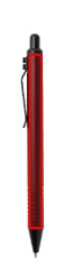

B

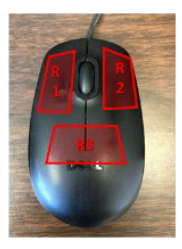

E

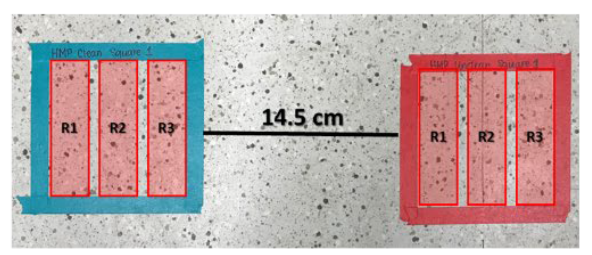

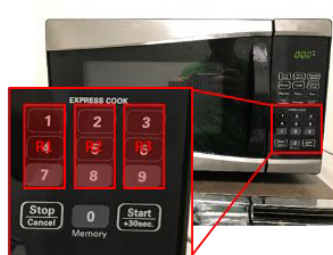

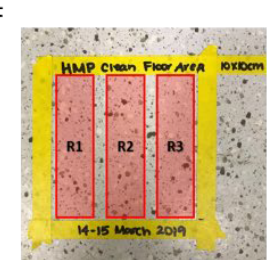

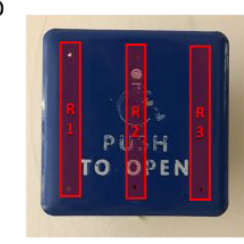

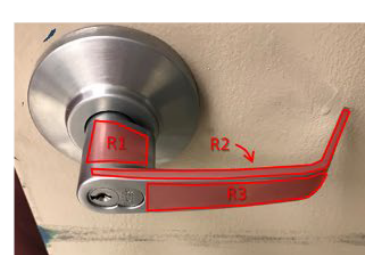

To remove molecular signatures before sampling, select surfaces were cleaned with the following solutions applied in order: 70\% ethanol, DNA Away (Molecular BioProducts Cat. \# 7010), and RNAse Away (Molecular BioProducts Cat. \# 7002). After the application of each cleaning solution, the surface was wiped with Kimwipes (Kimtech Science Cat. \# 34133). Surfaces that underwent cleaning prior to sampling are specified in Table 1.

\subsection{DNA extraction}

Prior to extraction, the DNA PowerSoil tubes containing the swabs were quickly thawed by hand warming. DNA was extracted using the Qiagen PowerSoil DNA extraction kit protocol (Qiagen, Cat. \# 12888-100) with the following exceptions. After addition of solution 1, samples were vortexed for at least 5 seconds to ensure complete distribution of solution 1. Tubes were incubated at $70^{\circ} \mathrm{C}$ for 5 minutes, vortexed for 5 seconds, and incubated at $70^{\circ} \mathrm{C}$ for 5 additional minutes. A DNA extraction blank was included with each set of DNA extractions.

\subsection{Quantitative polymerase chain reaction}

Quantitative polymerase chain reaction was performed to assess bacterial biomass per sample on a LightCycler 480 System (Roche Molecular Systems, Inc., Indianapolis, IN). The $16 \mathrm{~S}$ rRNA gene was amplified using the $331 \mathrm{~F} / 797 \mathrm{R}$ primer set and the hydrolysis probe BacTaq (Nadkarni et al. 2002). Each $20 \mu \mathrm{L}$ reaction contained $0.5 \mu \mathrm{M}$ of each primer, $5 \mathrm{uL}$ of DNA 
template, $125 \mathrm{nM}$ of probe, and $10 \mu \mathrm{L}$ of the LightCycler 480 Probes Master Mix (Roche Molecular Systems, Cat. \# 04887301001). The conditions for qPCR were as follows: a denaturation step of $95^{\circ} \mathrm{C}$ for 600 seconds followed by 45 cycles of $95^{\circ} \mathrm{C}$ for 30 seconds, $57^{\circ} \mathrm{C}$ for 60 seconds, $72^{\circ} \mathrm{C}$ for 25 seconds, and final extension at $40^{\circ} \mathrm{C}$ for 30 seconds. The cycle threshold value was identified using the second derivative maximum method. Each reaction was run in duplicate.

The absolute gene copy number for each sample was determined using an external calibration curve. Genomic DNA from Pseudomonas protegens (ATCC, Cat. \# BAA-477) was extracted using the UltraClean Microbial DNA isolation kit (MoBio Laboratories, Cat. \# 270676). The DNA concentration was measured using a Qubit fluorometer. The extracted DNA was serial diluted and $5 \mu \mathrm{L}$ of the DNA template was used per reaction for the standard curve. The $16 \mathrm{~S}$ gene copy number was calculated from the measured DNA concentration assuming six copies of the 16S rRNA gene per $P$. protegens organism. The reported copy number values are the average of three or four sample replicates.

\subsection{DNA sequencing}

Samples and controls for 16S rRNA gene sequencing were sent to the Environmental Sample Preparation and Sequencing Facility at the Argonne National Laboratory. In short, polymerase chain reaction (PCR) amplicon libraries targeting the $16 \mathrm{~S}$ rRNA gene present in genomic DNA were produced using a barcoded primer set adapted for the Illumina MiSeq (Caporaso et al. 2012), followed by the generation of DNA sequence data using Illumina paired-end sequencing. Specifically, the $\mathrm{V} 4$ region of the $16 \mathrm{~S}$ rRNA gene was PCR amplified with region-specific primers (515F/806R) that include sequencer adapter sequences used in the Illumina flowcell (Caporaso et al. 2011, 2012). The reverse amplification primer also contained a twelve-base barcode sequence (Caporaso et al. 2011, 2012). Each $25 \mu \mathrm{L}$ PCR reaction contained 9.5 $\mu \mathrm{L}$ of MO BIO PCR Water (Certified DNA-Free), $12.5 \mu \mathrm{L}$ of QuantaBio's AccuStart II PCR ToughMix (2x concentration, $1 \mathrm{x}$ final), $1 \mu \mathrm{L}$ of primer ( $5 \mu \mathrm{M}$ concentration, $200 \mathrm{pM}$ final), 1 $\mu \mathrm{L}$ of Golay barcode tagged primer ( $5 \mu \mathrm{M}$ concentration, $200 \mathrm{pM}$ final), and $1 \mu \mathrm{L}$ of template DNA. 
The conditions for PCR are as follows: $94^{\circ} \mathrm{C}$ for 3 minutes to denature the DNA followed by 35 cycles at $94^{\circ} \mathrm{C}$ for 45 seconds, $50^{\circ} \mathrm{C}$ for 60 seconds, and $72^{\circ} \mathrm{C}$ for 90 seconds with a final extension of 10 minutes at $72^{\circ} \mathrm{C}$ to ensure complete amplification. Amplicons were then quantified using PicoGreen (Invitrogen) and a plate reader (Infinite 200 PRO, Tecan). Once quantified, volumes of each of the products were pooled into a single tube so that each amplicon was represented in equimolar amounts. The pool was cleaned up using AMPure XP Beads (Beckman Coulter) and quantified using a fluorometer (Qubit, Invitrogen). After quantification, the molarity of the pool was determined and diluted down to $2 \mathrm{nM}$, denatured, and then diluted to a final concentration of $6.75 \mathrm{pM}$ with a 10\% PhiX spike for sequencing on the Illumina MiSeq. Amplicons were sequenced on a $151 \mathrm{bp}^{*} \times 12 \mathrm{bp} \times 151 \mathrm{bp}$ MiSeq run using customized sequencing primers and procedures (Caporaso et al. 2012).

\subsection{Sequence quality control and processing}

The forward and reverse read files were demultiplexed into individual files using the "split_libraries_fastq" script within QIIME 1.9 (Caporaso et al. 2010). Additionally, any remaining adapters or barcode sequences were removed, resulting in 11,393,776 reads in 114 samples. All data processing for quality control and taxonomic assignment was performed using the $\mathrm{R}$ package DADA2 (Callahan et al. 2016) with $R$ version 3.5.2 ( $R$ Core Team 2018). Briefly, forward and reverse reads were trimmed to exclude the first 20 base pairs (bp) of the forward reads and the first and last $20 \mathrm{bp}$ of the reverse reads. Additionally, reads were trimmed to exclude any base pair with a quality score of two or lower. Sequence reads that met the following criteria were removed from the analysis: contained ambiguous base pairs, had an expected error score of 2 or higher, read length less than $125 \mathrm{bp}$, or were PhiX reads. Introduced errors were estimated, and the resulting estimated error rates were visually examined for best fit. To infer amplicon sequence variants (ASV), redundant reads were dereplicated followed by pairwise alignments. Forward and reverse reads were merged, and chimeras were removed, leaving 10,429,749 total reads. Taxonomy was assigned using the naïve Bayseisan classifier method (Wang et al. 2007) and the Ribosomal Database Project (RDP) taxonomic training set 16 (Cole et al. 2014).

\footnotetext{
* Base pair.
} 
Acidobacteria taxonomic structure does not consistently include the hierarchy information used to assign taxonomic levels in DADA2 (phylum, class, order, family, genus) (Dedysh et al. 2018, Mizrahi-Man et al. 2013). As a result, when taxonomic data from the RDP database is parsed into the taxonomic levels in DADA2, a subset of Acidobacteria organisms are misassigned below the class level. To circumvent this, we exported the taxa table, manually curated the Acidobacteria taxonomic structure, and imported the new taxa table for use in phyloseq. This ensured that ASVs identified as the phylum Acidobacteria were no longer binned as "unassigned taxa" at the genus level when in fact a genus had been assigned.

\subsection{Sequence analysis}

The following methods were all performed using the R package phyloseq, version 1.26.1 (McMurdie and Holmes 2013); and visualizations were created in ggplot2 (Wickham 2016). The sequence variant table, taxonomic assignments, and sample metadata were combined together into one phyloseq object. Any taxa that did not possess a taxonomic designation at the phylum level were removed. ASVs that were identified as chloroplasts at the class level were removed. Alpha diversity was calculated from the ASV counts using the Shannon diversity index (Shannon 1948). Taxa counts were converted to relative abundance. Principal Coordinates Analysis (PCoA) was performed on $\log$-transformed $(\mathrm{y}=\log 1 \mathrm{O}(1+\mathrm{x}))$ relative abundances using the Bray-Curtis dissimilarity metric (Bray and Curtis 1957). 


\section{Results}

To test differences in biological signatures in the built environment, we collected samples from various locations around a working laboratory, including from office spaces and laboratory spaces (Table 1 and Figure 2). Locations included carpet located in an office shared by multiple people, the floor in a heavily used laboratory, buttons on a microwave in a shared common space, the handicap button on a heavily used dual door system, a door handle, and computer mice and pens at individuals' work stations (Table 1 and Figure 2).

\subsection{Detection of biological signatures in the built environment}

\subsubsection{Verification}

The first task was to verify the detection and reproducibility of biological signatures in the built environment with limited to no experimenter contamination. As a first step, we used qPCR of the 16S rRNA gene to determine total bacterial biomass from the sampled surfaces. Bacteria were detected in every sample (Figure 3 and Appendix A). However, the bacterial biomass in the swabbing controls and DNA extraction blank controls were low compared to the built-environment samples. For example, when comparing the average total bacterial biomass of all controls to samples collected from the floor, a computer mouse, and a pen, the total bacterial biomass of the controls were approximately 21, 30, and 15 times lower, respectively (Figure 3 and Appendix A), indicating successful collection and detection of biological signatures in the built environment.

The microbial communities in the control and built-environment samples were compared by examining PCoA dissimilarity plots created from $16 \mathrm{~S}$ rRNA gene DNA sequencing data. Figure 4 is a representative figure of these analyses. Samples collected from the floor, a computer mouse, and a pen clustered away from the controls (Figure 4). This indicates that the microbial communities collected from the built-environment samples (floor, computer mouse, and pen) were dissimilar to the controls. Furthermore, Shannon diversity was lower for the control samples (extraction blank and swab) compared to the built-environment samples (Figure 5), indicating both abundance and richness were lower in the control samples. 
Figure 3. Bacterial abundance detected in the built environment. The total bacterial biomass was determined by qPCR from selected samples: floor, computer mouse, pen, swabbing controls, and extraction blanks. The reported 16S rRNA gene copy number are the average of 3 or 4 replicates. Error bars represent the standard error. An asterisk denotes a reported average that includes values extrapolated outside the lower end of the standard curve.

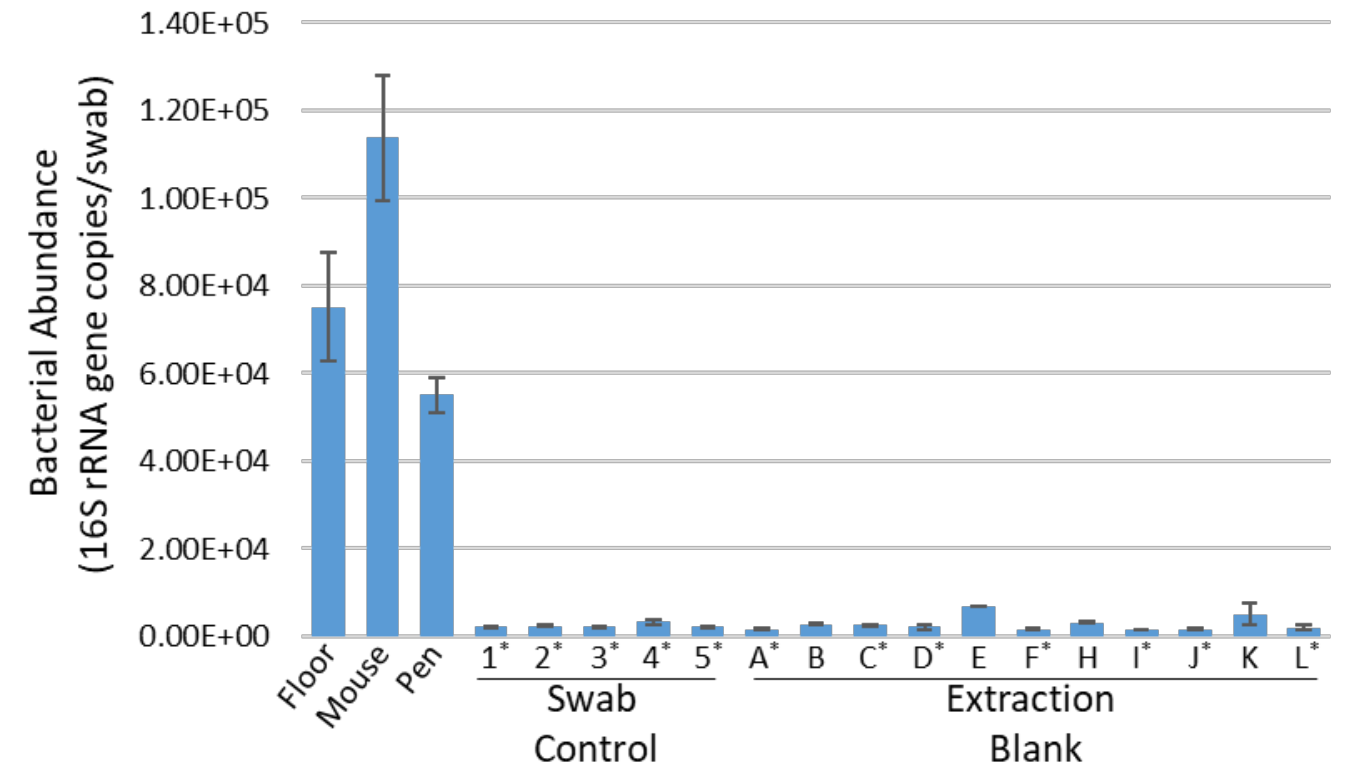

Figure 4. PCoA plot displaying microbial community dissimilarity between the controls (swab and blank) and built-environment samples using the Bray-Curtis dissimilarity metric.

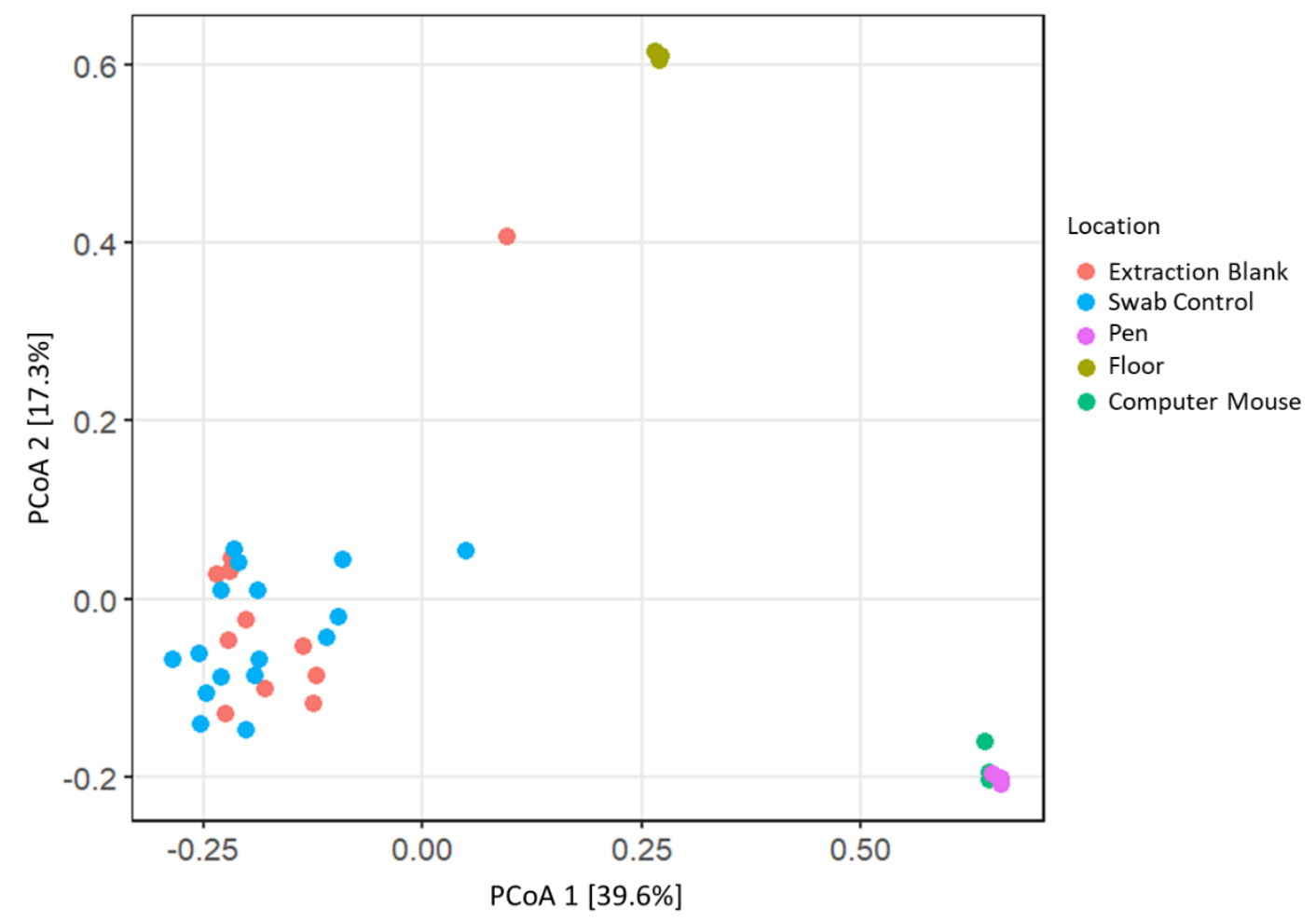


Figure 5. Box plots showing Shannon diversity of all samples.

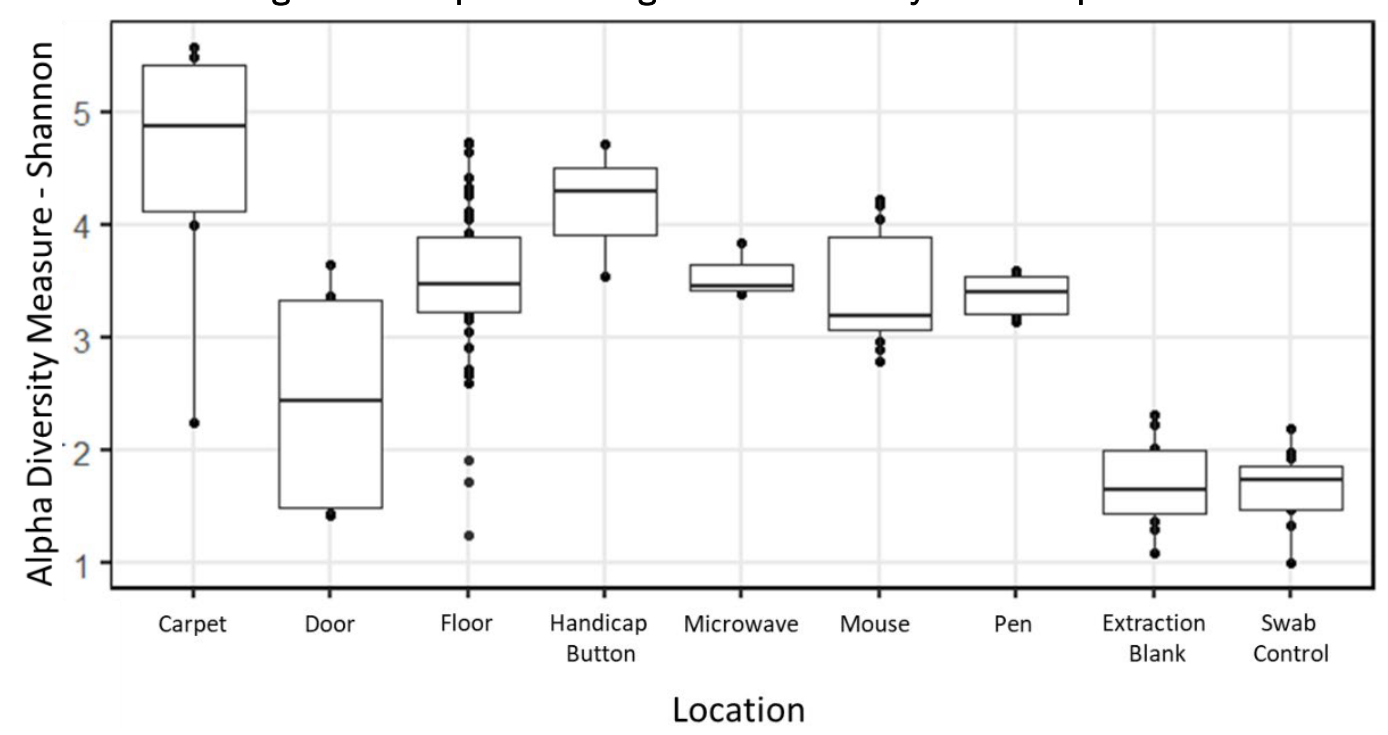

From these analyses, we determined that the sample-collection method used in the present study was successful in collecting microorganisms (bacteria and archaea) from the built environment, any contamination introduced from the swabs or DNA extraction kit did not alter the sampling results.

\subsubsection{Removal of biological signatures through cleaning}

To investigate if biological signatures could be removed from surfaces in the built environment, half of a selected item (computer mouse or door handle) was cleaned, (described in Table 1) prior to sampling. Swabbing was performed in triplicate on the clean and uncleaned surface of each object. Bacterial biomass and community diversity were compared to evaluate the cleaning procedure (Figure 6). Cleaning reduced the total bacterial biomass of both the computer mouse (75\% reduction) and the door handle (94\% reduction). However, the cleaned surface of the computer mouse was above the detected levels of the swab control (Figure 6A). Additionally, the clean door samples (Figure 6, red diamonds) clustered with the swabbing control samples (green diamonds), while the computer mouse samples (clean and unclean) clustered together (blue diamonds and blue triangles), indicating these sample communities were more similar to each other (Figure 6B). 
Figure 6. Removal of biological signatures in the built environment. Plots of $(A)$ total bacterial biomass and $(B)$ PCoA dissimilarity using the Bray-Curtis dissimilarity metric display signatures detected from a computer mouse and a door handle where one half of the object was cleaned prior to sampling. Error bars represent the standard error. An asterisk denotes a reported average that includes values extrapolated outside the lower end of the standard curve.

A
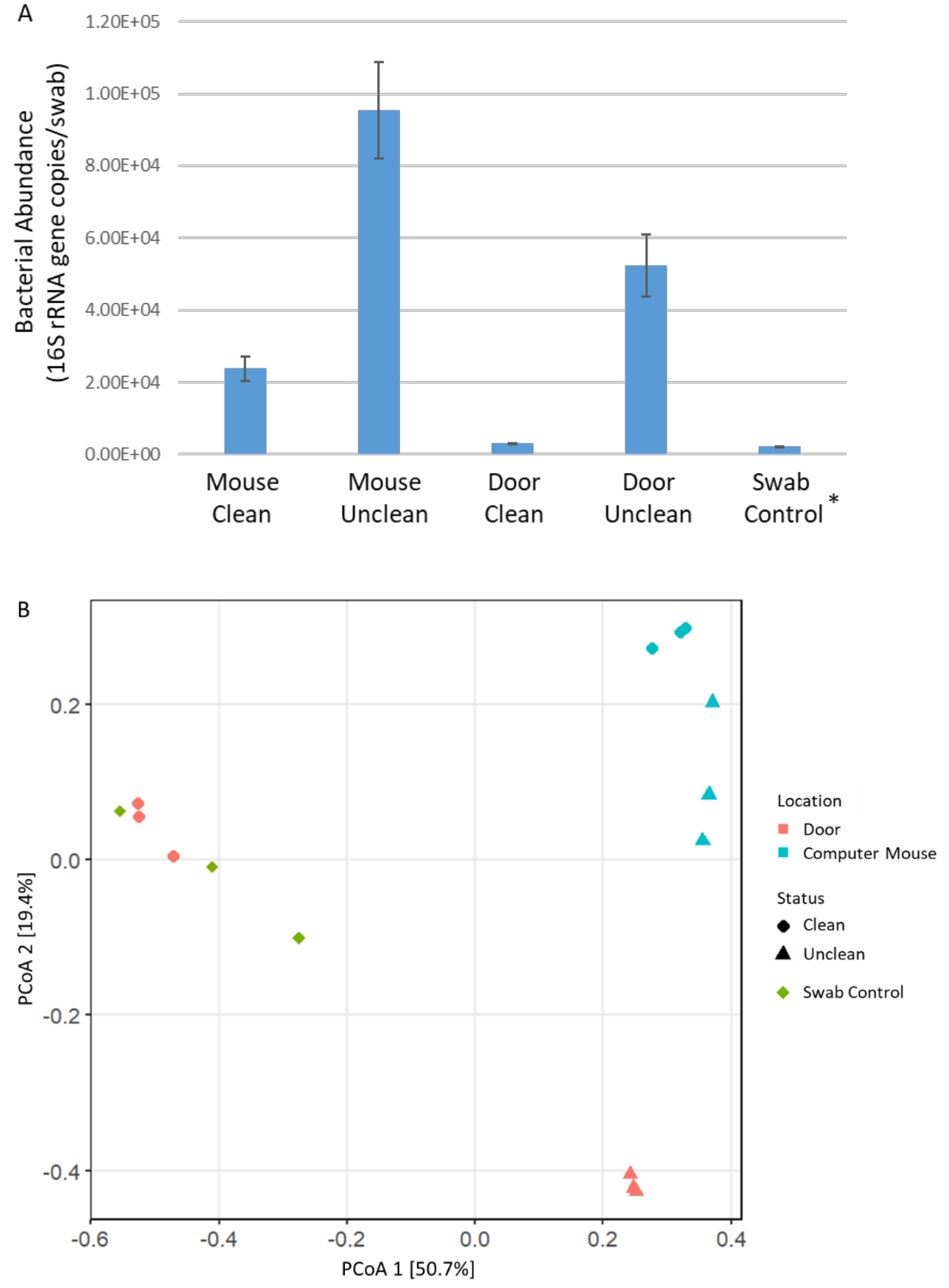
These data indicate that while cleaning resulted in a decline of the total bacterial biomass on both types of surfaces, the cleaning procedure was not as effective on the surface of the computer mouse. These results are not surprising as bacteria have been detected in fairly sterile built environments like cleanrooms and intensive care units (Mahnert et al. 2019). Interestingly, previous research in the built environment has been conducted in relation to pathogen removal efficiency (Josephson et al. 1997; Lesho et al. 2015) and microbial resistance (Mahnert et al. 2019; Fahimipour et al. 2018); but to our knowledge, an in-depth study of the impacts of direct cleaning on the microbiome of different indoor surfaces has yet to be conducted. Future studies will need to consider the item surface type and adapt cleaning methods as necessary.

\subsubsection{Investigation of wetting agents}

We tested the efficacy of two wetting agents, the nonionic detergent Tween20 with $\mathrm{NaCl}$ and PBS, for sample collection from the floor and carpet. The first two principal components captured $70.8 \%$ of the variance (Figure 7). The samples separated by sample location rather than wetting agent along PCoA1, which accounted for $54 \%$ of the variance explained by the ordination analysis (Figure 7). The reproducible community structure observed in the floor samples was not observed in samples collected from the carpet; this is expected as the carpet samples have large alpha diversity (Figure 7 and Figure 5). Two clusters were observed from the carpet-sample replicates (Figure 7). We expected these clusters to separate by wetting agent if the wetting agent impacted the groups of bacteria collected in the sample; however, the data does not reflect this. We do note that one PBS replicate is grouped with two of the T2O carpet replicates and vice versa, suggesting a handling error; however, due to study constraints, we could not verify this.

Our experiment demonstrated the importance of testing surface types and wetting agents prior to large-scale studies, as these factors may influence the resultant microbial community detected. Additionally, as the replicate samples of the carpet swabbing tests were not reproducible, we recommend that future collection of carpet samples use a vacuum with a filtration system attached as described in Sharma et al. (2019). 
Figure 7. PCoA diversity plot displaying similarities between samples collected from the floor and carpet by using either phosphate-buffered saline (PBS) or Tween20 in a $\mathrm{NaCl}$ solution (T20) as a wetting agent. Ordination was generated using the Bray-Curtis dissimilarity metric.

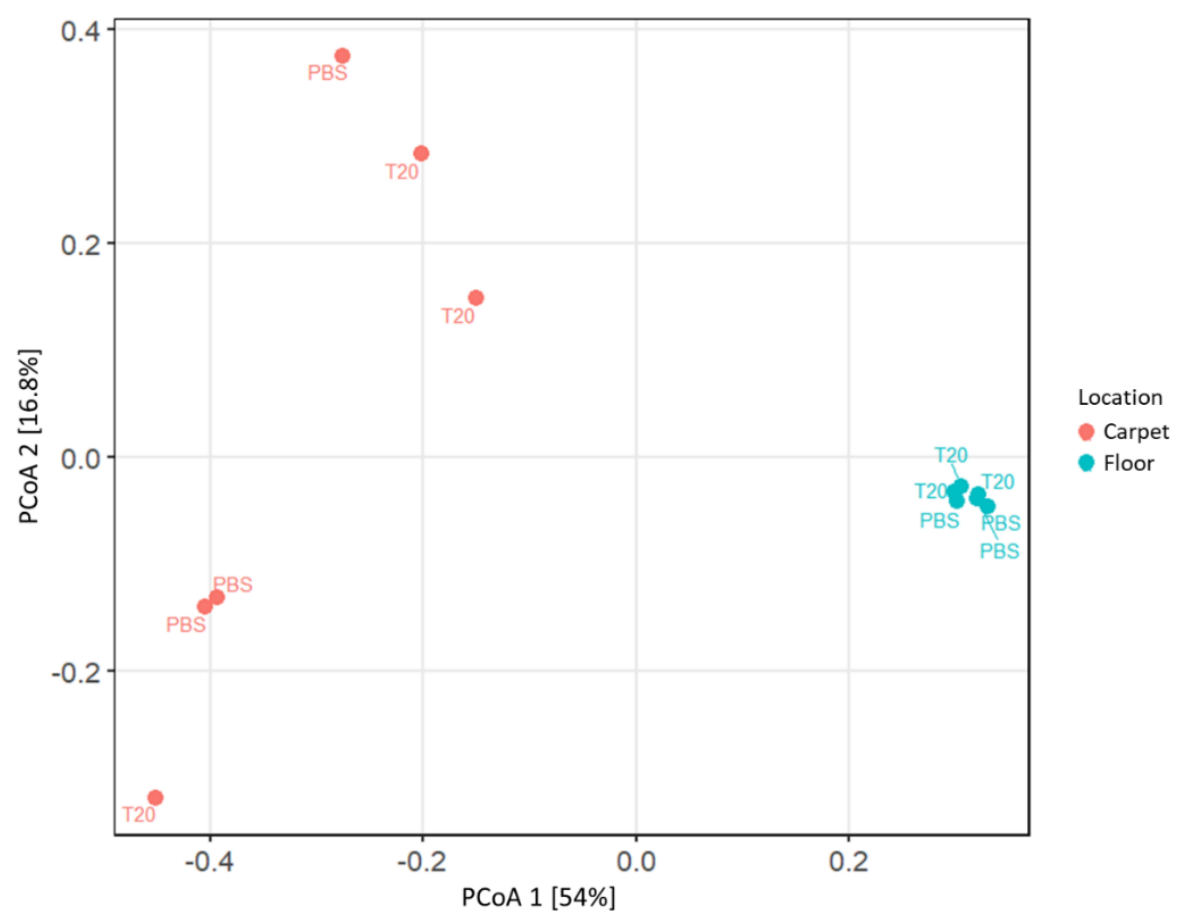

\subsection{Analysis of biological signatures on objects in the built environment}

\subsubsection{Survey of biological signatures on surfaces}

To investigate the how the microbial community structure varied on surfaces in the built environment, we analyzed the microbial community from select locations around a working laboratory. These locations consisted of two major groups: human-contact items and floor-surface locations (Table 1 and Figure 2). In the PCoA of all of the built-environment microbiomes, the first two principal components captured 59.4\% of the variance (Figure 8). Differences were observed along PCoA1 between the floor-surface samples (floor and carpet) and the human-contact samples (handicap button, microwave, pen, and computer mouse) (Figures 8 and 9). Interestingly, the floor-surface samples show dissimilarity to each other along PCoA1, with the carpet samples being more similar than the floor samples to the human-contact samples. Additionally, the human-contact samples show dissimilarity to each other along PCoA2 and dissimilarity to the floor-surface samples along PCoA1. 
The most abundant bacterial genera in the floor samples were Acinetobacter, Pseudomonas, and Massilia (Figure 9). High levels of Acinetobacter were expected as this is a genus commonly found in soil (Baumann 1968). Acinetobacter was also present in the carpet samples but at lower relative abundance (Figure 9). Interestingly, we observed higher relative abundance levels of Staphylococcus in the carpet samples than in the floor samples (Figure 9). Observing Staphylococcus in the built environment was expected as it is commonly found on skin (Byrd et al. 2018; Grice and Segre 2011) and can be deposited via desquamation (Meadow et al. 2015; Downing et al. 1982; Adams et al. 2015). The increased relative abundance on the carpet compared to hard flooring material might be due to the carpet fibers' ability to better retain biological particles (Dannemiller et al. 2017). Furthermore, we observed a higher alpha diversity between the carpet-sample replicates than the floor-sample replicates (Figures 5 and 9).

In general, the bacterial communities from the human-contact samples consisted of high relative abundance of Staphylococcus, Streptococcus, Pseudomonas, or Corynebacterium while the genus Acinetobacter (observed in the floor-surface samples) was less abundant (Figure 9). The bacterial communities in the three replicate samples from the handicap button were more similar to each other than the replicates from the microwave were. This is interesting as both items were exposed to a high number of different individuals. When an individual pushes the handicap button, they may be more likely to use the palm of their hand whereas people may use their fingers to push the buttons on a microwave. Perhaps, the variances in how people interact with objects account for the differences observed. One of the microwave replicates had a high abundance of bacteria from genus Lactococcus. Lactococci are lactic acid bacteria, and many species within this genus are used in the dairy industry as fermenters (Cavanagh et al. 2015). In the same replicate, Propionibacterium was present; members of this genus survive on the skin, for example around sebaceous glands (Brook and Frazier 1991; Mollerup et al. 2016). 
Figure 8. PCoA plot displaying dissimilarity between communities collected on indicated surface types in the built environment. Ordination was generated using the Bray-Curtis dissimilarity metric.

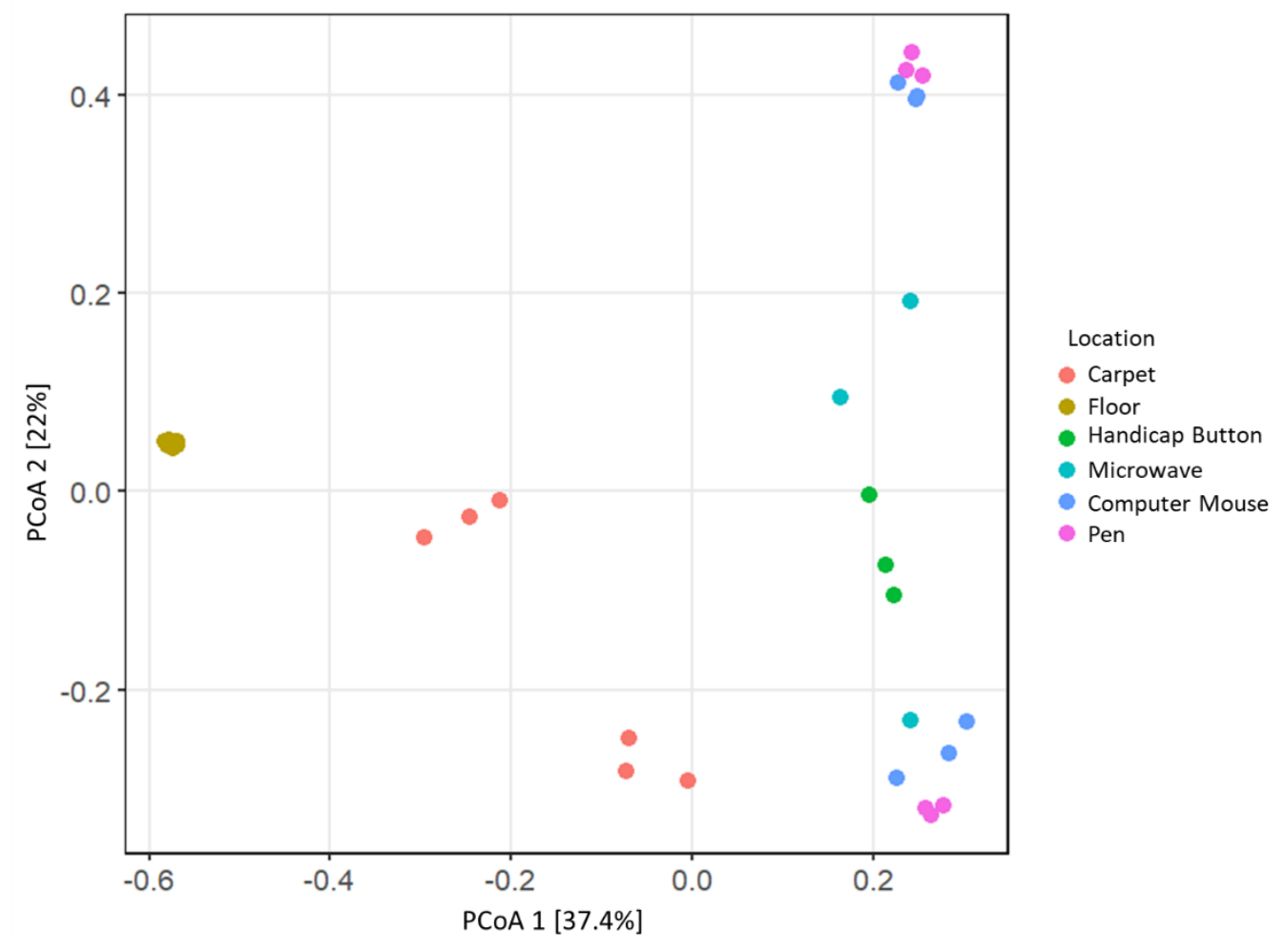


Figure 9. Bar chart displaying relative abundance of bacteria detected on objects in the built environment reported at the genus level. The legend lists the top twenty taxa.

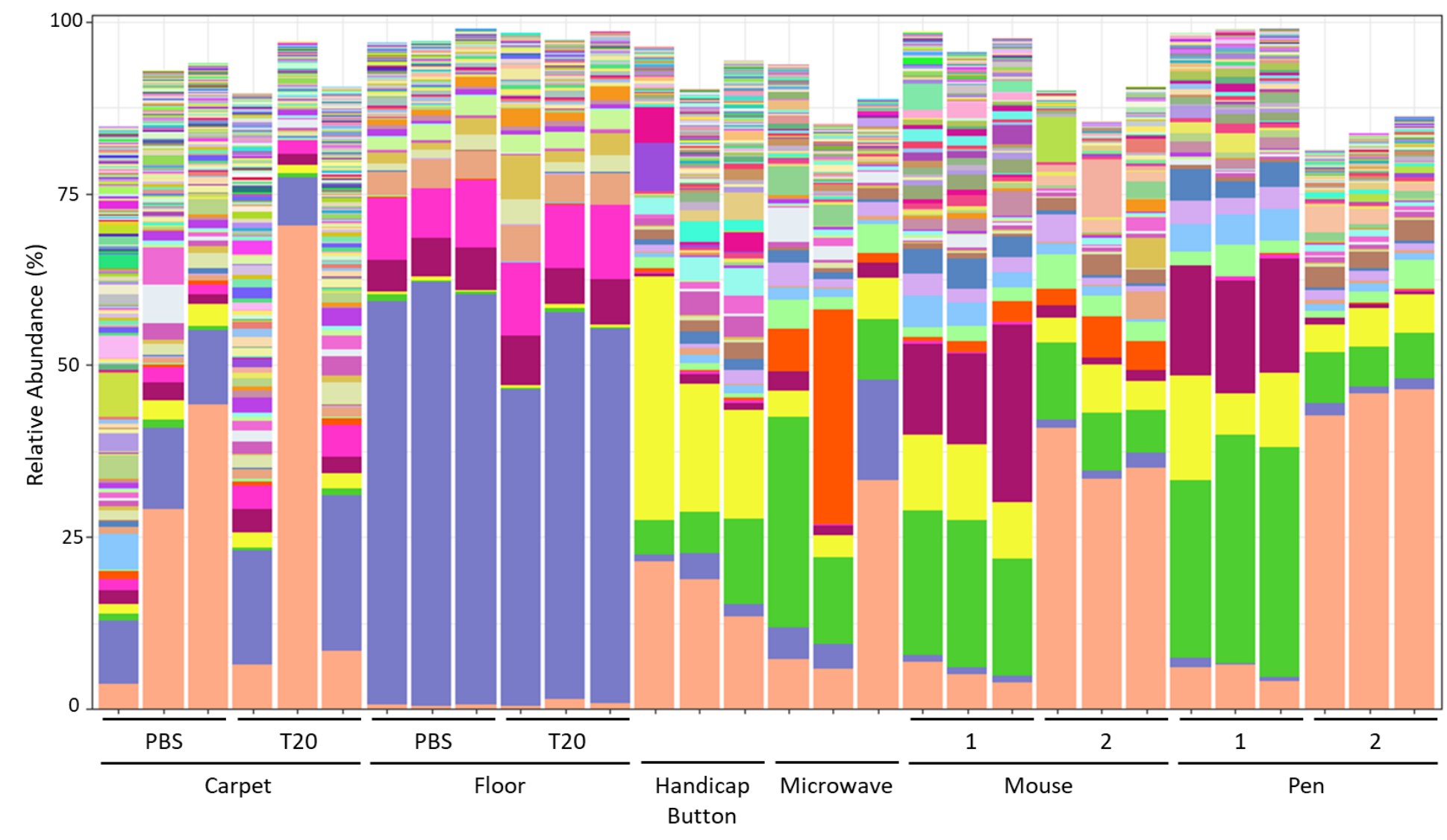

Genus

Staphylococcus

Acinetobacter

Streptococcus

Corynebacterium

Pseudomonas

Massilia

Lactococcus

Haemophilus

Neisseria

Paracoccus

Rothia

Actinomyces

Propionibacterium

Sphingomonas

Brevundimonas

Micrococcus

Lactobacillus

Kocuria

Stenotrophomonas

Anaerococcus 


\subsubsection{Microbial signatures used for fingerprinting}

We tested if we could discern items belonging to individuals by using the microbial biological signature that remains on an object. A computer mouse and a pen were swabbed at two individuals' workstations (workstation 1 and workstation 2). In the PCoA of the items, PCoA1 and PCoA2 captured $71.8 \%$ and $7.7 \%$ of the variance, respectively (Figure 10). Interestingly, samples separated along PCoA1 according to workstation rather than according to item (Figure 10), indicating microbial community similarity between the items from the same workstation and dissimilarity between items collected at different workstations. The relative abundance at the genus level demonstrated microbial patterns distinct to each of workstations (Figure 9).

To highlight this, Figure 11 displays the average relative abundance of selected bacteria. Workstation 1 (computer mouse 1 and pen 1) had low levels of Staphylococcus and high levels of Pseudomonas, whereas workstation 2 had high levels of Staphylococcus and low levels of Pseudomonas. The detected levels of Acinetobacter were not significantly different between the two workstations. This simplified example outlines how select bacteria or an individual's microbial community structure could be used as an identifier. However, further investigation is needed to develop methods to compare groups of individuals and to evaluate the strength of an individual's signature and the stability of that signature in the built environment using a machine learning approach. There are multiple machine learning algorithms in existence, but the most common for microbiome applications, due to its superior performance, is random forest (Topçuoğlu et al. 2020). Random forest uses a feature table consisting of samples with abundance information for either sequences or taxonomy and recognizes patterns for predictive outputs into like groups. More sampling than in the present study is necessary to have the statistical power to analyze a test and training dataset. Overall, the use of random forest machine learning has a promising application in microbiome forensics with humans shedding approximately $10^{6}$ microbial cells per hour, leaving behind a biological deposit that can be unique to each person (You and Chen 2013). 
Figure 10. PCoA plot displaying similarities between communities collected from computer mice and pens at two individuals' workstations. Ordination was generated using the Bray-Curtis dissimilarity metric.

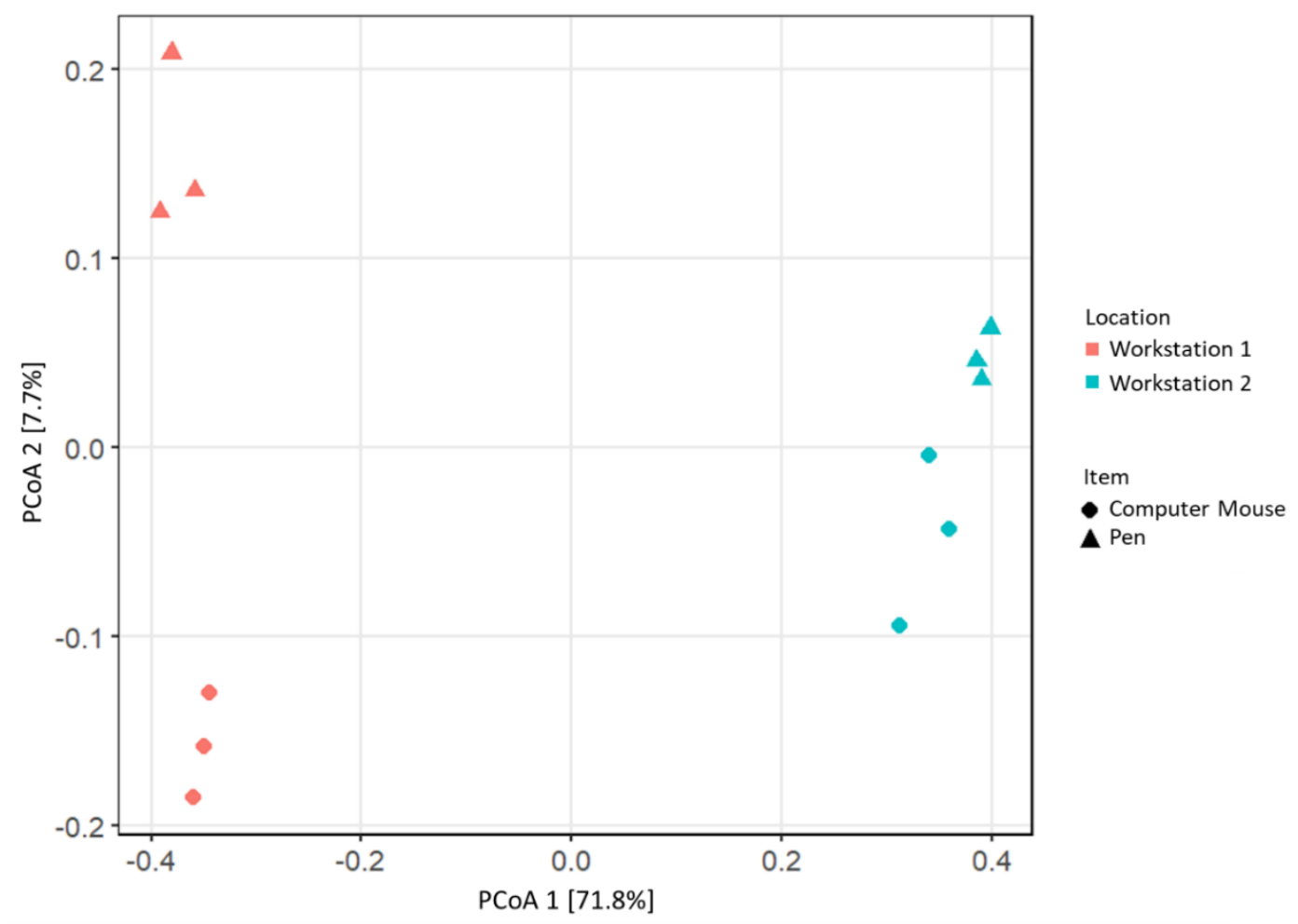

Figure 11. Average relative abundance of Staphylococcus, Acinetobacter, and Pseudomonas on items collected at workstation 1 and workstation 2. Sampling was performed in triplicate. Averages and standard deviations were calculated from the relative abundance.

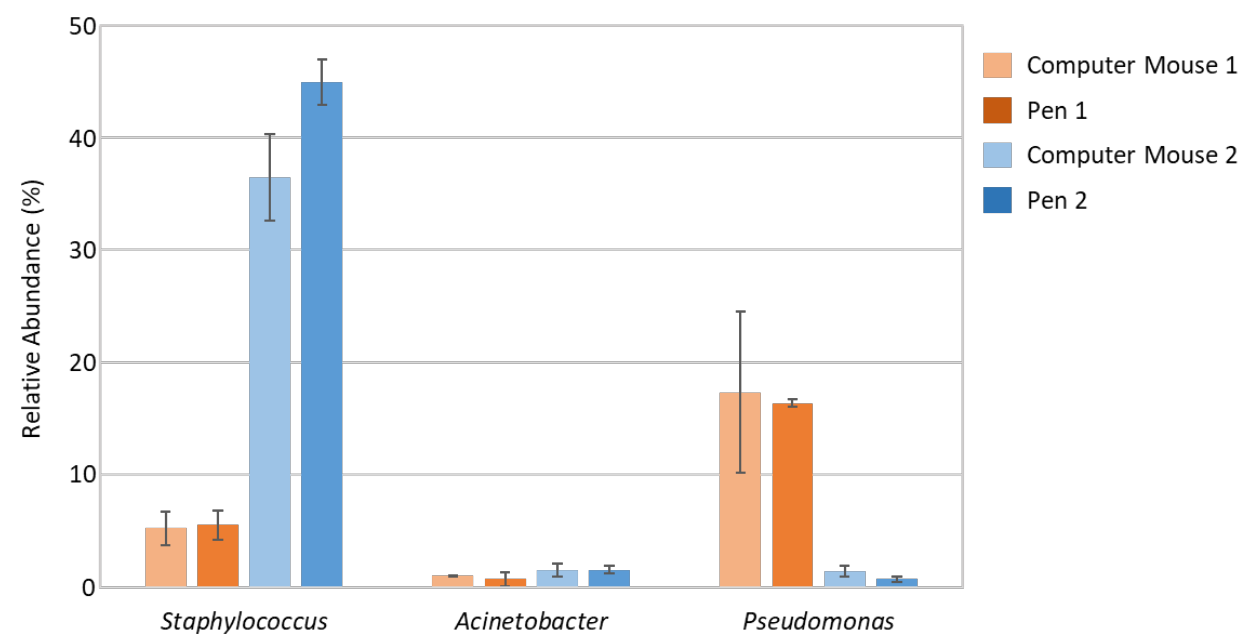




\subsection{Community succession in the built environment}

\subsubsection{Longitudinal changes in microbiomes of the built environment}

To investigate recolonization of a microbial community, we measured longitudinal changes in the floor microbiome after the removal of the biological signatures. Sampling of a $10 \times 10 \mathrm{~cm}$ square of floor was performed after cleaning $\left(t_{0}\right), 1$ day $\left(t_{1}\right)$, and 43 days $\left(t_{43}\right)$. When examining the bulk bacterial biomass, there was a 1.37-fold increase between $t_{0}$ and $t_{1}$ and a 49.2-fold increase between $t_{0}$ and $t_{43}$ (Appendix A). We observed differences between $t_{0}$ and $t_{1}$ communities along PCoA 2 and $t_{43}$ along PCoA 1 (Figure 12). We also observed variance between the individual replicates from each of the first two time points (Figures 12 and 13). After 43 days $\left(t_{43}\right)$, the replicates were similar in both taxa composition and abundance, indicating the community reached an equilibrium (Figures 12 and 13).

Figure 12. PCOA plot displaying biological signatures detected on the floor after cleaning $\left(t_{0}\right), 1$ day $\left(t_{1}\right)$, and 43 days $\left(t_{43}\right)$. Arrows indicate the progression of the community. Ordination was generated using the Bray-Curtis dissimilarity metric.

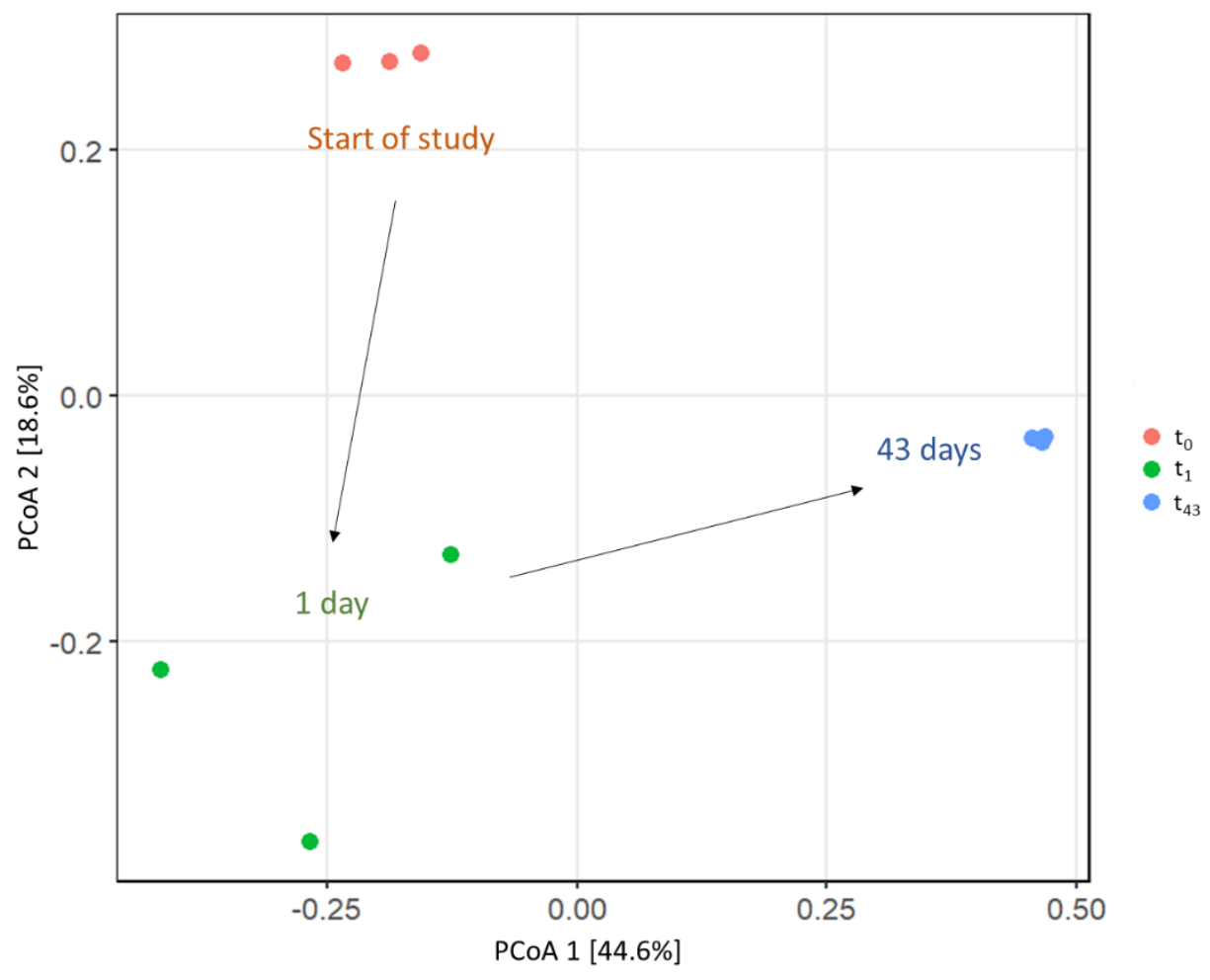


Figure 13. Bar chart displaying relative abundance at the genus level of floor samples immediately $\left(t_{0}\right), 1$ day $\left(t_{1}\right)$, and 43 days $\left(t_{43}\right)$ after cleaning. Swabbing at each time point was performed in triplicate. The legend lists the top twenty taxa.

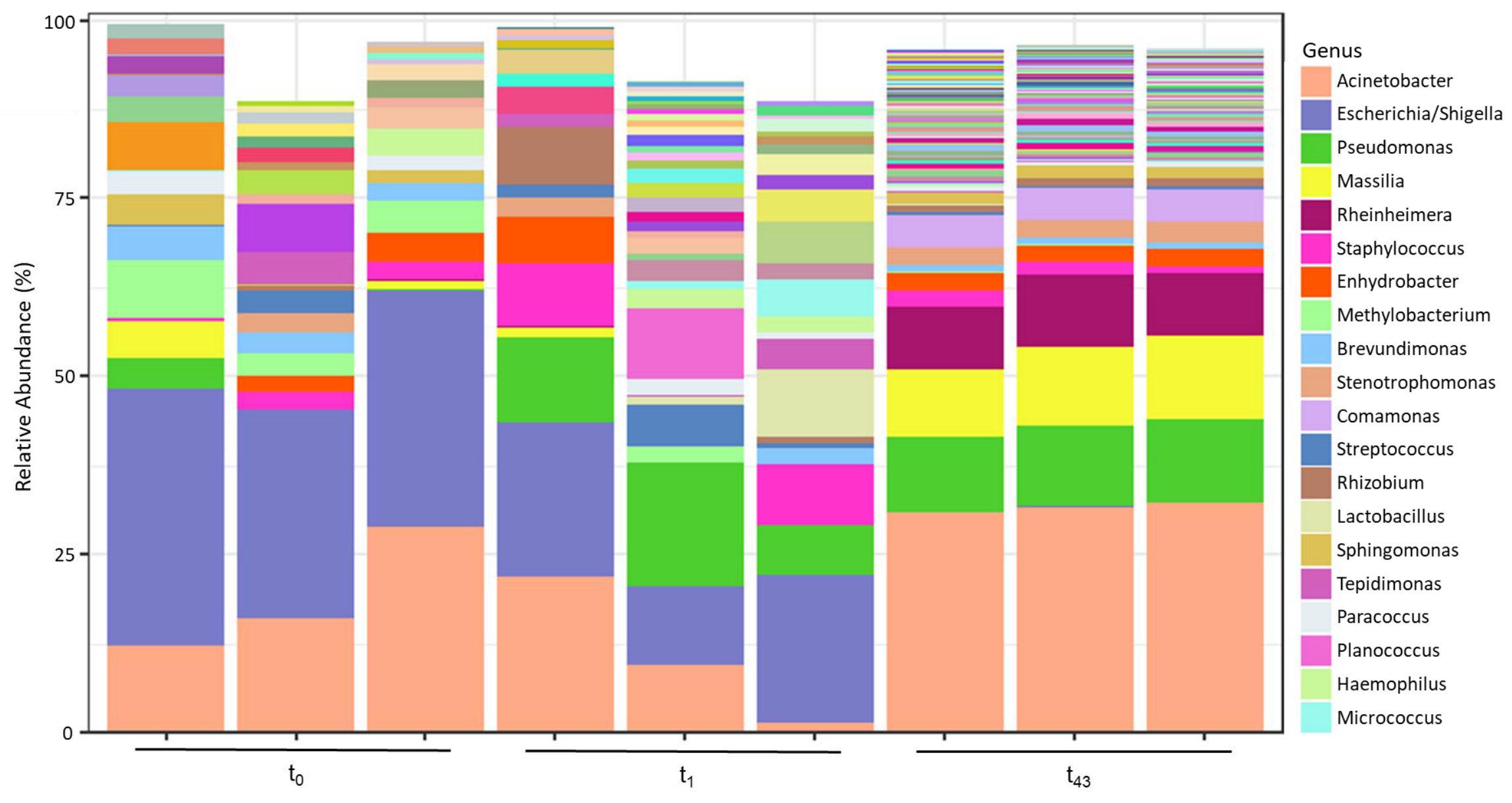




\subsubsection{Microbiome response to perturbation}

We further investigated recolonization and succession of microbial communities by surveying microbial communities with and without a disturbance event (cleaning) over time. Three locations of a laboratory floor were sampled: section 1 (S1), section 2 (S2), and section 3 (S3) (Figure 14). Each section consisted of two squares, one that was disturbed (clean) and one that was not disturbed (unclean) (cleaning described in Table 1). Within each square, we collected three replicate swabbing samples (R1, R2, and R3) (Figure 14 and Figure 2E). Each section was sampled at the beginning of the experiment $\left(t_{0}\right)$ and 43 days $\left(t_{43}\right)$ later. Sampling locations were subject to routine daily use, including janitorial services during the course of the experiment.

Figure 14. Diagram of experimental setup (not to scale). Each location was sampled at the beginning of the experiment ( $\left.t_{0}\right)$ and 43 days $\left(t_{43}\right)$ later.

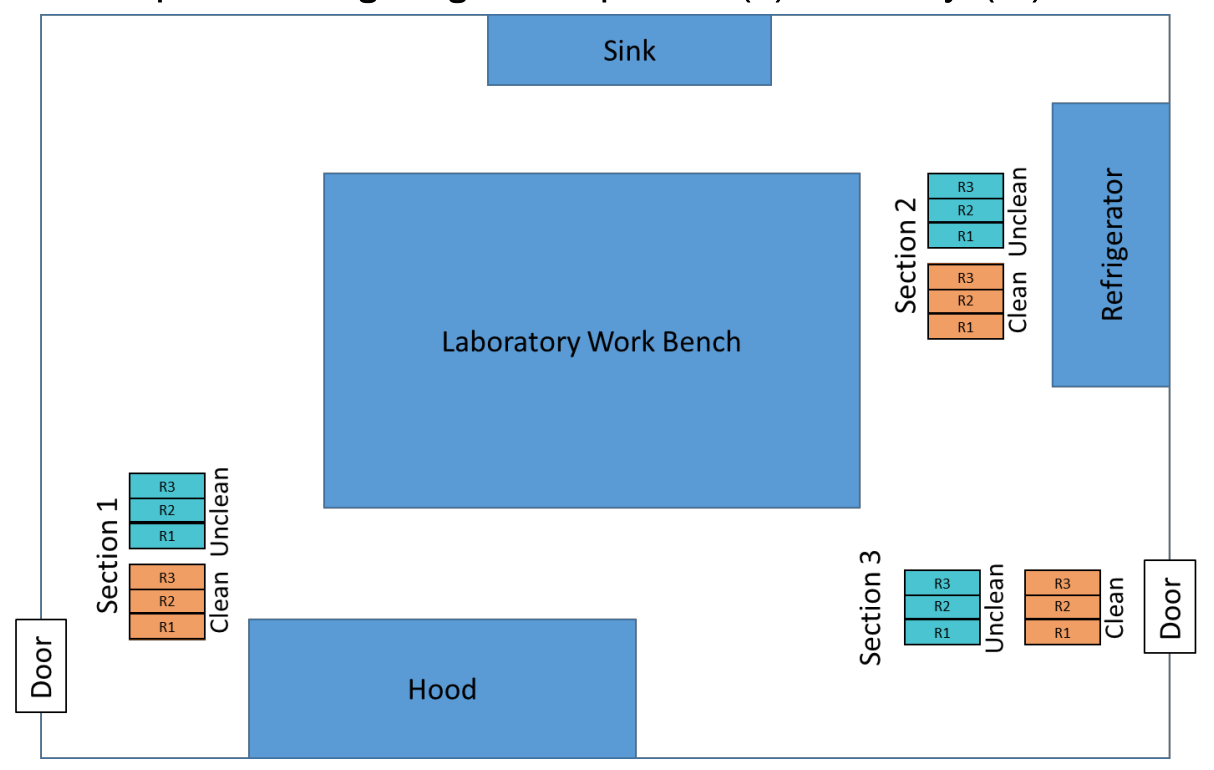

The microbial communities of all three floor locations initial ( $\left.t_{0}\right)$ unclean square replicates ( $\mathrm{S} 1 t_{0}$ unclean, $\mathrm{S} 2 t_{\mathrm{o}}$ unclean, and $\mathrm{S} 3 t_{\mathrm{o}}$ unclean) formed a tight cluster on the PCoA plot (Figure 15, S1, S2 and S3 blue diamonds) and show similar community composition (Figure 16). The initial $\left(t_{0}\right)$ unclean squares, regardless of room location, lacked microbial community differences, indicating a stable starting community. 
Cleaning the squares (disturbance event) reduced the total bacterial biomass (Appendix A) and changed the microbial community structure (compare blue diamonds to red diamonds, Figure 15). The $S_{3}$ to clean samples showed the greatest change due to the disturbance event, with a shift along PCoA 2 and a steep decline in community diversity (Figures 15 and 16). The $\mathrm{S} 1 t_{0}$ clean and $\mathrm{S} 2 t_{0}$ clean samples ( $\mathrm{S} 1$ and $\mathrm{S} 2$ red diamonds) cluster closer to the $t_{0}$ unclean samples (S1, $\mathrm{S} 2$, and $\mathrm{S} 3$ blue diamonds), indicating that a higher proportion of the starting community remained after cleaning (Figure 15). The greater diversity observed in these samples compared to the $S_{3} t_{0}$ clean samples further supports this notion (Figure 16).

Figure 15. PCoA plot displaying biological signatures detected on clean and unclean squares located within three sections of the floor (S1, S2, and S3) at the start of the experiment ( $\left.t_{0}\right)$ and 43 days $\left(t_{43}\right)$ later. Arrows indicate the progression of the community. Ordination was generated based on the BrayCurtis dissimilarity metric.

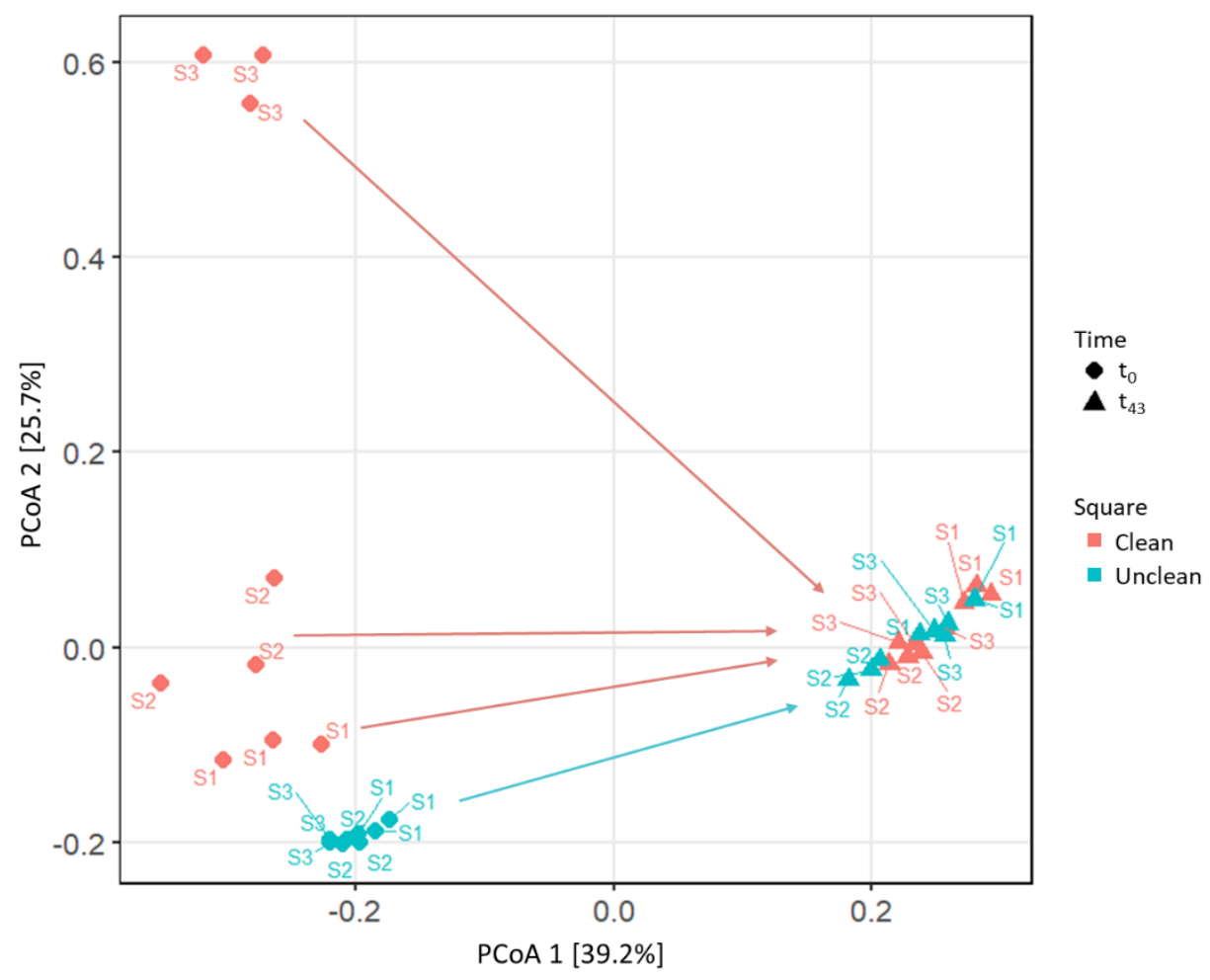


Figure 16. Relative abundance of floor samples immediately ( $\left.t_{0}\right)$ and 43 days ( $\left.t_{43}\right)$ after the disturbance event (cleaning). Swabbing was performed in triplicate at each square for each time point. The legend lists the top twenty taxa.

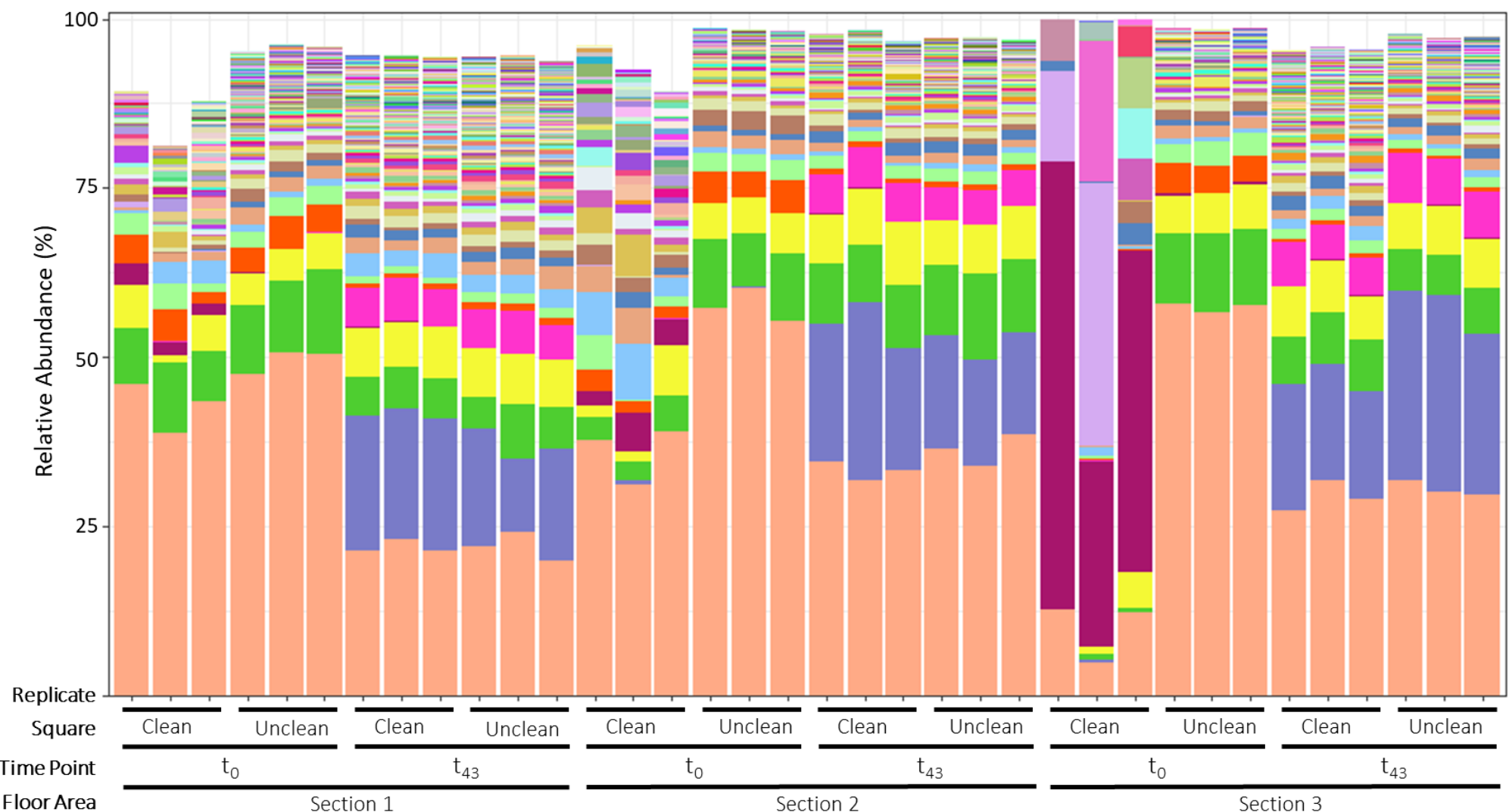

Genus

Acinetobacter

Rheinheimera

Massilia

Pseudomonas

Escherichia/Shigella

Comamonas

Paracoccus

Stenotrophomonas

Staphylococcus

Sphingomonas

Alcaligenes

Enhydrobacter

Brevundimonas

Chryseobacterium

Corynebacterium

Flavobacterium

Streptococcus

Aliivibrio

Rhizobium

Methylobacterium

Floor Area

Section 1

Section 2

Section 3 
After 43 days, the cleaned and uncleaned microbial communities were similar regardless of the cleaning treatment, as demonstrated by their close proximity on the PCoA graph (all blue and red triangles, Figure 15). Interestingly, the community after 43 days was different from the starting community (Figures 15 and 16). Generally, there was a decrease in Acinetobacter and an increase of Comamonas between the initial community ( $t_{\mathrm{o}}$ unclean samples) and the final community (all $t_{43}$ samples) (Figure 16). The appearance of Rheinheimera in all of the $t_{43}$ samples is interesting as it was not present in the initial community, indicating introduction during the course of the experiment.

Though we observed differences between the initial and final community, microbial community structure in between these end states is unknown. More time points would elucidate whether the community had a consistent or irregular trajectory. This would inform better forecasting for forensics applications. 


\section{Conclusions}

Here we demonstrated our ability to detect microbial signatures in the built environment. Microbial signatures were quantified, and analysis of the community structures showed clear taxonomy and community differences between touched items and ground samples. In fact, our data show that microbial community data could effectively link an individual to an object. Additionally, these preliminary studies investigated community progression and the establishment of community stability after a disturbance event.

Bio-signatures originating from human skin could provide timely information on groups of individuals who are occupying or were passing through a particular location. Human-associated microbes found in the built environment have clear advantages since the microbes

a. are indicative of occupants;

b. may undergo characteristic time-evolution pathways, allowing us to gauge time since the presence of the original human host;

c. carry information about recent activity patterns (e.g., food, sleep, health, and locations visited) and cultural characteristics;

d. could be hard to counter, as a person sheds one million skin cells per day with associated microbiota; and

e. may provide information on family associates through shared microbes.

More-detailed studies are needed to develop methods to compare groups of individuals and to evaluate the strength of an individual's signature and the stability of that signature in the built environment. Finally, the role of disturbance (i.e., cleaning products or introduction of a new individual) and how it may impact the trajectory of the microbial communities is poorly understood. If the microbial communities undergo succession in repeatable patterns, then it may be possible to predict the time that the disturbance occurred. Research in this area would therefore offer new, innovative technologies to track individuals in the built environment. 


\section{References}

Adams, R. I., M. Miletto, J. W. Taylor, and T. D. Bruns. 2013. "Dispersal in Microbes: Fungi in Indoor Air Are Dominated by Outdoor Air and Show Dispersal Limitation at Short Distances." The ISME Journal 7 (7): 1262-73. https://doi.org/10.1038/ismej.2013.28.

Adams, R. I., S. Bhangar, W. Pasut, E. A. Arens, J. W. Taylor, S. E. Lindow, W. W. Nazaroff, and T. D. Bruns. 2015. "Chamber Bioaerosol Study: Outdoor Air and Human Occupants as Sources of Indoor Airborne Microbes.” Edited by Y. Zhang. PLOS ONE 10 (5): e0128022. https://doi.org/10.1371/journal.pone.0128022.

Barberán, A., R. R. Dunn, B. J. Reich, K. Pacifici, E. B. Laber, H. L. Menninger, J. M. Morton, J. B. Henley, J. W. Leff, S. L. Miller, and N. Fierer. 2015. "The Ecology of Microscopic Life in Household Dust." Proceedings of the Royal Society B: Biological Sciences 282 (1814). https://doi.org/10.1098/rspb.2015.1139.

Baumann, P. 1968. "Isolation of Acinetobacter from Soil and Water." Journal of Bacteriology 96 (1): 39-42.

Bray, J. R., and J. T. Curtis. 1957. "An Ordination of the Upland Forest Communities of Southern Wisconsin.” Ecological Monographs 27 (4): 325-49. https://doi.org/10.2307/1942268.

Brook, I., and E. H. Frazier. 1991. "Infections Caused by Propionibacterium Species." Clinical Infectious Diseases 13 (5): 819-22. https://doi.org/10.1093/clinids/13.5.819.

Byrd, A. L., Y. Belkaid, and J. A. Segre. 2018. “The Human Skin Microbiome.” Nature Reviews Microbiology 16 (3): 143-55. https://doi.org/10.1038/nrmicro.2017.157.

Callahan, B. J., P. J. McMurdie, M. J. Rosen, A. W. Han, A. J. A. Johnson, and S. P. Holmes. 2016. "DADA2: High-Resolution Sample Inference from Illumina Amplicon Data." Nature Methods 13 (7): 581-83. https://doi.org/10.1038/nmeth.3869.

Caporaso, J. G., J. Kuczynski, J. Stombaugh, K. Bittinger, F. D. Bushman, E. K. Costello, N. Fierer, A. Gonzalez Peña, J. K. Goodrich, J. I. Gordon, G. A. Huttley, S. T. Kelley, D. Knights, J. E. Koenig, R. E. Ley, C. A. Lozupone, D. McDonald, B. D. Muegge, M. Pirrung, J. Reeder, J. R. Sevinsky, P. J. Turnbaugh, W. A. Walters, J. Widmann, T. Yatsunenko, J. Zaneveld, and R. Knight. 2010. "QIIME Allows Analysis of High-Throughput Community Sequencing Data.” Nature Methods 7 (5): 335-36. https://doi.org/10.1038/nmeth.f.303.

Caporaso, J. G., C. L. Lauber, W. A. Walters, D. Berg-Lyons, C. A. Lozupone, P. J. Turnbaugh, N. Fierer, and R. Knight. 2011. "Global Patterns of 16S RRNA Diversity at a Depth of Millions of Sequences per Sample." Proceedings of the National Academy of Sciences of the United States of America 108 Suppl 1 (March): 4516-22. https://doi.org/10.1073/pnas.1000080107. 
Caporaso, J. G., C. L. Lauber, W. A. Walters, D. Berg-Lyons, J. Huntley, N. Fierer, S. M. Owens, J. Betley, L. Fraser, M. Bauer, N. Gormley, J. A. Gilbert, G. Smith, and R. Knight. 2012. "Ultra-High-Throughput Microbial Community Analysis on the Illumina HiSeq and MiSeq Platforms.” The ISME Journal 6 (8): 1621-24. https://doi.org/10.1038/ismej.2012.8.

Cavanagh, D., G. F. Fitzgerald, and O. McAuliffe. 2015. "From Field to Fermentation: The Origins of Lactococcus Lactis and Its Domestication to the Dairy Environment." Food Microbiology 47 (May): 45-61. https://doi.org/10.1016/j.fm.2014.11.001.

Chen, Y. E., and H. Tsao. 2013. "The Skin Microbiome: Current Perspectives and Future Challenges." Journal of the American Academy of Dermatology 69 (1): 143-55. https://doi.org/10.1016/i.jaad.2013.01.016.

Cole, J. R., Q. Wang, J. A. Fish, B. Chai, D. M. McGarrell, Y. Sun, C. T. Brown, A. PorrasAlfaro, C. R. Kuske, and J. M. Tiedje. 2014. "Ribosomal Database Project: Data and Tools for High Throughput rRNA Analysis. Nucleic Acids Research 42 (D1): D633-D642. https://doi.org/10.1093/nar/gkt1244.

Dannemiller, K. C., C. J. Weschler, and J. Peccia. 2017. "Fungal and Bacterial Growth in Floor Dust at Elevated Relative Humidity Levels." Indoor Air 27 (2): 354-63. https://doi.org/10.1111/ina.12313.

Dedysh, S. N., and P. Yilmaz. 2018. "Refining the Taxonomic Structure of the Phylum Acidobacteria." International Journal of Systematic and Evolutionary Microbiology 68 (12): 3796-3806. https://doi.org/10.1099/ijsem.0.003062.

Downing, D. T., A. M. Stranieri, and J. S. Strauss. 1982. "The Effect of Accumulated Lipids on Measurements of Sebum Secretion in Human Skin.” The Journal of Investigative Dermatology 79 (4): 226-28. https://doi.org/10.1111/15231747.ep12500066.

Fahimipour, A. K., S. B. Mamaar, A. G. McFarland, R. A. Blaustein, J. Chen, A. J. Glawe, J. Kline, J. L. Green, R. U. Halden, K. Van Den Wymelenberg, C. Huttenhower, and E. M. Hartmann. 2018. "Antimicrobial Chemicals Associate with Microbial Function and Antibiotic Resistance Indoors.” Edited by J. K. Jansson. MSystems 3 (6). https://doi.org/10.1128/mSystems.00200-18.

Gibbons, S. M., T. Schwartz, J. Fouquier, M. Mitchell, N. Sangwan, J. A. Gilbert, and S. T. Kelley. 2015. "Ecological Succession and Viability of Human-Associated Microbiota on Restroom Surfaces." Applied and Environmental Microbiology 81 (2): 765-73. https://doi.org/10.1128/AEM.03117-14.

Grice, E. A., and J. A. Segre. 2011. "The Skin Microbiome." Nature Reviews Microbiology 9 (4): 244-53. https://doi.org/10.1038/nrmicro2537.

Gupta, V. K., S. Paul, and C. Dutta. 2017. "Geography, Ethnicity or Subsistence-Specific Variations in Human Microbiome Composition and Diversity." Frontiers in Microbiology 8: 1162. https://doi.org/10.3389/fmicb.2017.01162. 
Holbert, A. B., H. P. Whitelam, L. J. Sooter, L. A. Hornak, and J. M. Dawson. 2015. "Hand Bacteria as an Identifier: A Biometric Evaluation." Network Modeling Analysis in Health Informatics and Bioinformatics 4 (1). https://doi.org/10.1007/s13721-0150095-0.

Hospodsky, D., A. J. Pickering, T. R. Julian, D. Miller, S. Gorthala, A. B. Boehm, and J. Peccia. 2014. "Hand Bacterial Communities Vary across Two Different Human Populations.” Microbiology (Reading, England) 160 (Pt 6): 1144-52. https://doi.org/10.1099/mic.0.075390-0.

Hu, Y., X. Yang, J. Qin, N. Lu, G. Cheng, N. Wu, Y. Pan, Human Microbiome Project Consortium. 2012. "Structure, Function and Diversity of the Healthy Human Microbiome.” Nature 486 (7402): 207-14. https://doi.org/10.1038/nature11234.

Josephson, K. L., J. R. Rubino, and I. L. Pepper. 1997. “Characterization and Quantification of Bacterial Pathogens and Indicator Organisms in Household Kitchens with and without the Use of a Disinfectant Cleaner." Journal of Applied Microbiology 83 (6): 737-50. https://doi.org/10.1046/j.1365-2672.1997.00308.x.

Kelley, S. T., and J. A. Gilbert. 2013. "Studying the Microbiology of the Indoor Environment." Genome Biology 14 (2): 202. https://doi.org/10.1186/gb-2013-14-2-202.

Lax, S., D. P. Smith, J. Hampton-Marcell, S. M. Owens, K. M. Handley, N. M. Scott, S. M. Gibbons, P. Larsen, B. D. Shogan, S. Weiss, J. L. Metcalf, L. K. U., Y. VázquezBaeza, W. Van Treuren, N. A. Hasan, M. K. Gibson, R. Colwell, G. Dantas, R. Knight, and J. A. Gilbert. 2014. "Longitudinal Analysis of Microbial Interaction between Humans and the Indoor Environment." Science 345 (6200): 1048-52. https://doi.org/10.1126/science.1254529.

Lesho, E., P. Carling, E. Hosford, A. Ong, E. Snesrud, M. Sparks, F. Onmus-Leone, N. Dzialowy, S. Fraser, Y. Kwak, S. Miller, U. Chukwuma, M. Julius, P. McGann, and R. Clifford. 2015. "Relationships among Cleaning, Environmental DNA, and Healthcare-Associated Infections in a New Evidence-Based Design Hospital." Infection Control \& Hospital Epidemiology 36 (10): 1130-38. https://doi.org/10.1017/ice.2015.151.

Leung, M. H. Y., D. Wilkins, and P. K. H. Lee. 2015. "Insights into the Pan-Microbiome: Skin Microbial Communities of Chinese Individuals Differ from Other Racial Groups." Scientific Reports 5 (July): 11845. https://doi.org/10.1038/srep11845.

Li, J., L. Zhu, X. Wang, Z. Meng, F. Zhao, D. Liu, J. Ma, N. Qin, C. Xiang, Y. Xiao, L. Li, H. Yang, J. Wang, R. Yang, G. F. Gao, J. Wang, and B. Zhu. 2013. "MetagenomeWide Analysis of Antibiotic Resistance Genes in a Large Cohort of Human Gut Microbiota." Nature Communications 4: 2151. https://doi.org/10.1038/ncomms3151.

Luongo, J. C., A. Barberán, R. Hacker-Cary, E. E. Morgan, S. L. Miller, and N. Fierer. 2017. "Microbial Analyses of Airborne Dust Collected from Dormitory Rooms Predict the Sex of Occupants." Indoor Air 27 (2): 338-44. https://doi.org/10.1111/ina.12302. 
Mahnert, A., C. Moissl-Eichinger, M. Zojer, D. Bogumil, I. Mizrahi, T. Rattei, J. Luis Martinez, and G. Berg. 2019. "Man-Made Microbial Resistances in Built Environments.” Nature Communications 10 (1). https://doi.org/10.1038/s41467019-08864-0.

McMurdie, P. J., and S. Holmes. 2013. "Phyloseq: An R Package for Reproducible Interactive Analysis and Graphics of Microbiome Census Data.” Edited by M. Watson. PLoS ONE 8 (4): e61217. https://doi.org/10.1371/journal.pone.0061217.

Meadow, J. F., A. E. Altrichter, A. C. Bateman, J. Stenson, G. Z. Brown, J. L. Green, and B. J. M. Bohannan. 2015. "Humans Differ in Their Personal Microbial Cloud." PeerJ 3: e1258. https://doi.org/10.7717/peerj.1258.

Mizrahi-Man, O., E. R. Davenport, and Y. Gilad, Y. 2013. "Taxonomic Classification of Bacterial 16S rRNA genes Using Short Sequencing Reads: Evaluation of Effective Study Designs." PloS ONE 8 (1): e53608. https://doi.org/10.1371/journal.pone.0053608.

Mollerup, S., J. Friis-Nielsen, L. Vinner, T. A. Hansen, S. R. Richter, H. Fridholm, J. A. Romero Herrera, O. Lund, S. Brunak, J. M. G. Izarzugaza, T. Mourier, L. P. Nielsen, and A. J. Hansen. 2016. "Propionibacterium Acnes: Disease-Causing Agent or Common Contaminant? Detection in Diverse Patient Samples by NextGeneration Sequencing." Edited by C.-A. D. Burnham. Journal of Clinical Microbiology 54 (4): 980-87. https://doi.org/10.1128/JCM.02723-15.

Nadkarni, M. A., F. E. Martin, N. A. Jacques, and N. Hunter. 2002. "Determination of Bacterial Load by Real-Time PCR Using a Broad-Range (Universal) Probe and Primers Set." Microbiology 148 (1): 257-66. https://doi.org/10.1099/00221287-1481-257.

Nishijima, S., W. Suda, K. Oshima, S.-W. Kim, Y. Hirose, H. Morita, and M. Hattori. 2016. "The Gut Microbiome of Healthy Japanese and Its Microbial and Functional Uniqueness." DNA Research: An International Journal for Rapid Publication of Reports on Genes and Genomes 23 (2): 125-33. https://doi.org/10.1093/dnares/dsw002.

Pakpour, S., J. A. Scott, S. E. Turvey, J. R. Brook, T. K. Takaro, M. R. Sears, and J. Klironomos. 2016. "Presence of Archaea in the Indoor Environment and Their Relationships with Housing Characteristics." Microbial Ecology 72 (2): 305-12. https://doi.org/10.1007/s00248-016-0767-z.

Pehrsson, E. C., P. Tsukayama, S. Patel, M. Mejía-Bautista, G. Sosa-Soto, K. M. Navarrete, M. Calderon, L. Cabrera, W. Hoyos-Arango, M. T. Bertoli, D. E. Berg, R. H. Gilman, and G. Dantas. 2016. "Interconnected Microbiomes and Resistomes in Low-Income Human Habitats." Nature 533 (7602): 212-16. https://doi.org/10.1038/nature17672.

Qin, J., R. Li, J. Raes, M. Arumugam, K. S. Burgdorf, C. Manichanh, T. Nielsen, N. Pons, F. Levenez, T. Yamada, D. R. Mende, J. Li, J. Xu, S. Li, D. Li, J. Cao, B. Wang, H. Liang, H. Zheng, Y. Xie, J. Tap, P. Lepage, M. Bertalan, J.-M. Batto, T. Hansen, D. Le Paslier, A. Linneberg, H. B. Nielsen, E. Pelletier, P. Renault, T. SicheritzPonten, K. Turner, H. Zhu, C. Yu, S. Li, M. Jian, Y. Zhou, Y. Li, X. Zhang, S. Li, N. 
Qin, H. Yang, J. Wang, S. Brunak, J. Doré, F. Guarner, K. Kristiansen, O. Pedersen, J. Parkhill, J. Weissenbach, MetaHIT Consortium, P. Bork, S. D. Ehrlich, and J. Wang. 2010. "A Human Gut Microbial Gene Catalogue Established by Metagenomic Sequencing." Nature 464 (7285): 59-65. https://doi.org/10.1038/nature08821.

R Core Team. 2018. R: A Language and Environment for Statistical Computing. Version R 3.5.2. Vienna, Austria: R Foundation for Statistical Computing. http://www.Rproject.org/.

Rintala, H., M. Pitkäranta, M. Toivola, L. Paulin, and A. Nevalainen. 2008. "Diversity and Seasonal Dynamics of Bacterial Community in Indoor Environment." $B M C$ Microbiology 8 (April): 56. https://doi.org/10.1186/1471-2180-8-56.

SanMiguel, A., and E. A. Grice. 2015. "Interactions between Host Factors and the Skin Microbiome." Cellular and Molecular Life Sciences: CMLS 72 (8): 1499-1515. https://doi.org/10.1007/s00018-014-1812-z.

Shannon, C. E. 1948. "A Mathematical Theory of Communication.” Bell System Technical Journal 27 (3): 379-423. https://doi.org/10.1002/i.1538-7305.1948.tb01338.x.

Sharma, A., M. Richardson, L. Cralle, C. E. Stamper, J. P. Maestre, K. A. Stearns-Yoder, T. T. Postolache, K. L. Bates, K. A. Kinney, L. A. Brenner, C. A Lowry, J. A. Gilbert, and A. J. Hoisington. 2019. "Longitudinal Homogenization of the Microbiome between Both Occupants and the Built Environment in a Cohort of United States Air Force Cadets." Microbiome 7:70. https://doi.org/10.1186/s40168019-0686-6.

Topçuoğlu, B. D., N. A. Lesniak, M. Ruffin, J. Wiens, and P. D. Schloss. 2020. “A Framework for Effective Application of Machine Learning to Microbiome-Based Classification Problems. BioRxiv 816090. https://doi.org/10.1101/816090.

Tung, J., L. B. Barreiro, M. B. Burns, J.-C. Grenier, J. Lynch, L. E. Grieneisen, J. Altmann, S. C. Alberts, R. Blekhman, and E. A. Archie. 2015. "Social Networks Predict Gut Microbiome Composition in Wild Baboons." ELife 4 (March). https://doi.org/10.7554/eLife.05224.

Wang, Q., G. M. Garrity, J. M. Tiedje, and J. R. Cole. 2007. "Naive Bayesian Classifier for Rapid Assignment of RRNA Sequences into the New Bacterial Taxonomy." Applied and Environmental Microbiology 73 (16): 5261-67. https://doi.org/10.1128/AEM.00062-07.

Weikl, F., C. Tischer, A. J. Probst, J. Heinrich, I. Markevych, S. Jochner, and K. Pritsch. 2016. "Fungal and Bacterial Communities in Indoor Dust Follow Different Environmental Determinants." PloS ONE 11 (4): e0154131. https://doi.org/10.1371/journal.pone.0154131.

Wickham, H. 2016. ggplot2: Elegant Graphics for Data Analysis. 2nd ed. New York: Springer Verlag. https://ggplot2.tidyverse.org. 
You, R., and C. Chen. 2013. "Measuring the Short-Term Emission Rates of Particles in the 'Personal Cloud' with Different Clothes and Activity Intensities in a Sealed Chamber." Aerosol and Air Quality Research 13 (3): 911-21. https://doi.org/10.4209/aaqr.2012.03.0061. 


\section{Appendix A: Supplemental Figure}

Figure A-1. Bacterial abundance detected in the built environment. The total bacterial biomass was determined by qPCR from all samples, swabbing controls, and extraction blanks. The reported 16S rRNA gene copy number are the average of 3-4 replicates. Error bars represent the standard error. An asterisk denotes a reported average that includes values extrapolated outside the lower end of the standard curve.

$1.80 \mathrm{E}+05$

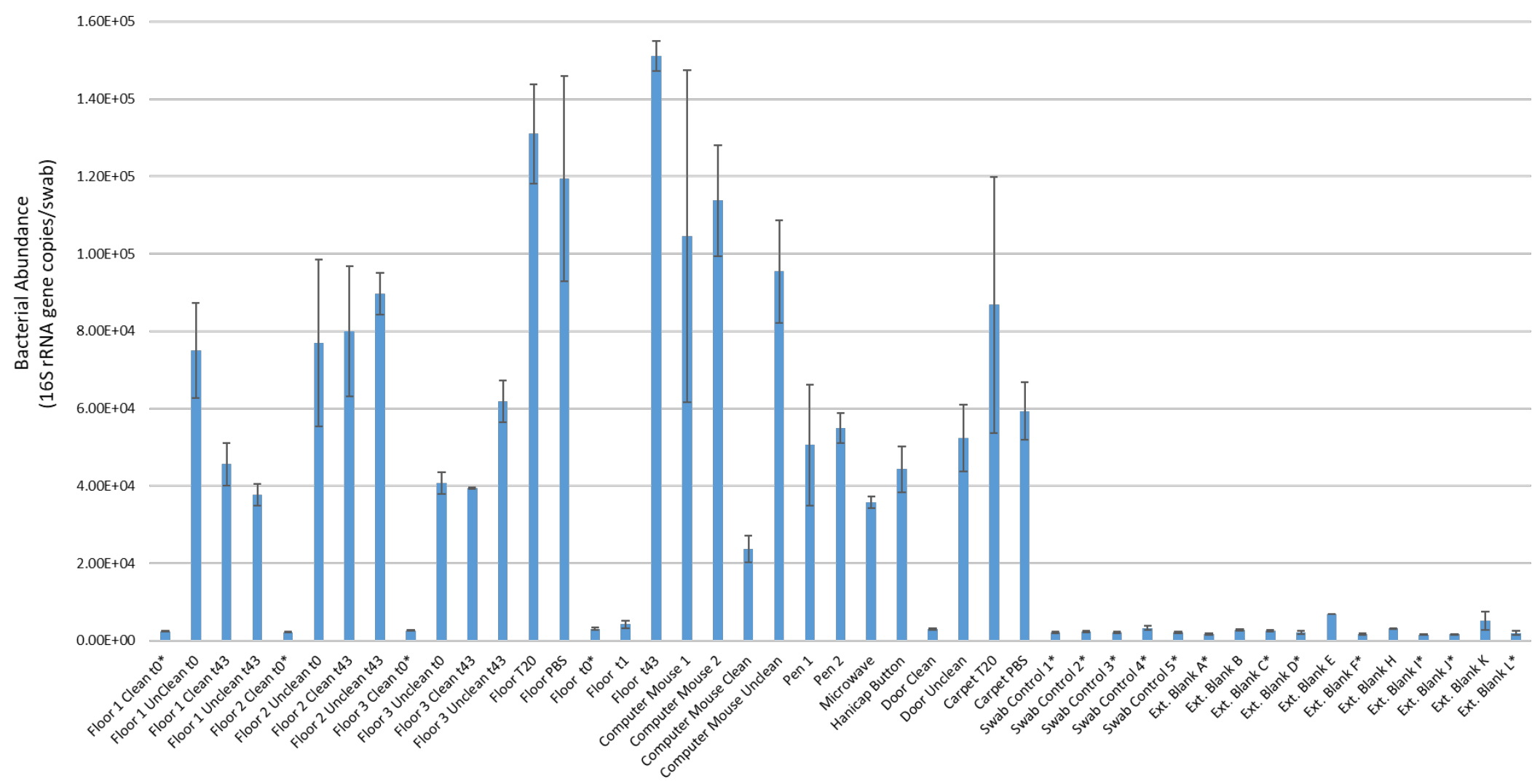




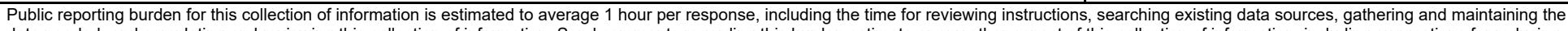

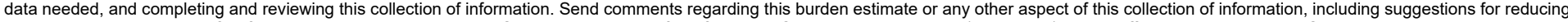

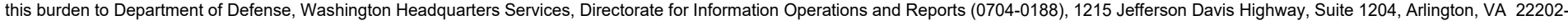

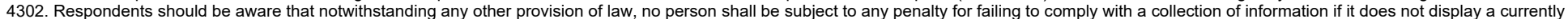
valid OMB control number. PLEASE DO NOT RETURN YOUR FORM TO THE ABOVE ADDRESS.

\section{REPORT DATE (DD-MM-YYYY) \\ 2. REPORT TYPE}

September 2020

4. TITLE AND SUBTITLE

Technical Report / Final

Microbiological Indicators Reflect Patterns of Life

\section{DATES COVERED (From - To)} FY19

5a. CONTRACT NUMBER

5b. GRANT NUMBER

5c. PROGRAM ELEMENT

611102

5d. PROJECT NUMBER

T24

5e. TASK NUMBER

A1000

5f. WORK UNIT NUMBER

8. PERFORMING ORGANIZATION REPORT NUMBER

ERDC TR-20-22
72 Lyme Road, Hanover, NH 03755-1290

U.S. Army Engineer Research and Development Center (ERDC) Geospatial Research Laboratory (GRL)

Cude Bldg. 2592, 7701 Telegraph Road

Alexandria, VA 22315-3864

\section{SPONSORING / MONITORING AGENCY NAME(S) AND ADDRESS(ES)}

Headquarters, U.S. Army Corps of Engineers

Washington, DC 20314-1000
10. SPONSOR/MONITOR'S ACRONYM(S) USACE

11. SPONSOR/MONITOR'S REPORT NUMBER(S)

\section{DISTRIBUTION / AVAILABILITY STATEMENT}

Approved for public release; distribution is unlimited.

\section{SUPPLEMENTARY NOTES}

6.1 ERDC Basic Research

\section{ABSTRACT}

Resolving patterns of human movement, specifically for actors of interest, in an urban environment is an extremely challenging problem because of the dynamic nature of human movement. This research effort explores a highly unconventional approach, addressing residual or lingering signatures of interest to the Army in an urban operation. Research suggests that unconventional signatures commonly associated with human presence or prior occupation of a space, such as microbes attached to skin cells or in the gut, may linger for an extended amount of time. In this scoping study, our objectives were to detect microbial communities in the built environment, to examine microbial community composition, and to investigate the longevity of a microbial signature. To do so, we conducted a controlled study to obtain a mechanistic understanding of the fidelity of the biological signatures in the built environment, with a particular focus on their longevity and stability.

\section{SUBJECT TERMS}

Bacteria, Biological signatures, Built environment, Community succession, Disturbance, Human beings--Microorganisms--Detection, Human microbiome, Microbial diversity, Military intelligence

\section{SECURITY CLASSIFICATION OF:}

a. REPORT
Unclassified
b. ABSTRACT
Unclassified

\begin{tabular}{|c|c|c|}
$\begin{array}{c}\text { 17. LIMITATION } \\
\text { OF ABSTRACT }\end{array}$ & $\begin{array}{c}\text { 18. NUMBER } \\
\text { OF PAGES }\end{array}$ & \\
\cline { 3 - 3 } SAR & 45 & \\
& &
\end{tabular}

\section{c. THIS PAGE}

Unclassified 19b. TELEPHONE NUMBER (include area code) 